\title{
Executive-process interactive control: A unified computational theory for answering 20 questions (and more) about cognitive ageing
}

\author{
David E. Meyer, Jennifer M. Glass, Shane T. Mueller, \\ Travis L. Seymour, and David E. Kieras \\ University of Michigan, USA
}

\begin{abstract}
Although the effects of ageing on human information processing and performance have been studied extensively, many fundamental questions about cognitive ageing remain to be answered definitively. For example, what are the sources of age-related slowing? How much is working-memory capacity reduced in older adults? Is time-sharing ability lost with age? Answering such questions requires a unified computational theory that characterises the interactive operations of many component mental processes and integrates diverse data on cognitive ageing. Toward fulfilling this requirement, an executive-process interactive control (EPIC) architecture has been extended to model performance of both young and older adults. EPIC models yield accurate accounts of ageing effects on reaction times and accuracy in basic dual-task and working-memory paradigms. From these accounts, it appears that time-sharing ability and working-memory capacity decrease relatively little until after 70 years of age. Before age 70 , at least some apparent performance decrements may be attributable to conservative executive processes and inefficient task procedures rather than decreased "hardware" functionality. By clarifying and deepening such insights, unified computational theories like EPIC will help answer many questions about cognitive ageing.
\end{abstract}

Requests for reprints should be addressed to D.E. Meyer, Cognition and Perception Program, Department of Psychology, University of Michigan, 525 East University, Ann Arbor, MI 48109-1109, USA. Email: demeyer@umich.edu

This paper is based on research supported in part by grant N00014-92-J-1173 from the United States Office of Naval Research to the University of Michigan, David E. Kieras, and David E. Meyer, Principal Investigators. We thank Ulrich Mayr, Reinhold Kliegl, Steven Keele, Trey Hedden, and participants of the Potsdam Conference on Aging and Executive Control for helpful suggestions and criticisms. Contributions by members of the Brain, Cognition, and Action Laboratory (David Fencsik, Leon Gmeindl, Cerita Jones, Ryan Kettler, Erick Lauber, Eric Schumacher, Molly Schweppe, and Eileen Zurbriggen) at the University of Michigan are also gratefully acknowledged.

(C) 2001 Psychology Press Ltd 


\section{INTRODUCTION}

The effects of ageing on cognition are pervasive and complex (Craik \& Salthouse, 2000). Within the human information-processing system, many interconnected components mediate perception, attention, memory, decision, and other mental processes. Ageing may affect the capabilities of each component, but the magnitudes of these effects may differ from one component to the next, and their contributions to the performance of particular tasks may depend on various contextual factors. Thus, to characterise cognitive ageing thoroughly and veridically requires answering many fundamental questions about the nature of age-related changes in information processing and task performance.

During the 20th century, few of these questions were answered definitively by theories of cognitive ageing. In our opinion, several related factors contributed to this slow progress:

(1) Definitions of basic concepts such as mental energy, processing resource, memory capacity, task complexity, and executive control have not been sufficiently rigorous (Salthouse, 1988).

(2) Too little consideration has been given to how complicated interactions between perceptual-motor and cognitive mechanisms change with age.

(3) Explicit distinctions between the information-processing system's "hardware" and "software", which are both affected by ageing, have remained mostly unarticulated.

(4) Contributions of alternative strategies for performing various tasks have yet to be modelled in detail and used for interpreting age-related declines in ability.

(5) Retarded skill acquisition has received relatively little emphasis in assessments of decreased information-processing capacities and task performance due to ageing.

Because of these limitations, controversies still exist over the answers to many questions about cognitive ageing. For example, is there a principal processing resource whose declining capacity mediates age-related slowing? Do older adults have substantially less working-memory capacity than young adults? Are older adults' mechanisms of selective attention and inhibitory control significantly impaired? Is time-sharing ability lost with age? Regarding each of these questions, some researchers have answered positively, and others negatively.

To make progress toward the correct answers, further theoretical developments are required. One way of satisfying this requirement has been suggested by Newell $(1973,1990)$. He argued that to win the game of 20 
Questions with Mother Nature, cognitive psychology needs general unified computational theories. These theories must include both an "architecture" that embodies the components of the information-processing system's "hardware", and a set of heuristic guidelines for how the system's "software" should be programmed to perform various tasks.

Such a unified theory may have great benefits (Newell, 1990). On the basis of it, diverse results from research on cognition and action can be integrated. This integration may reveal strong constraints that these results impose. By incorporating these constraints, models of performance in many tasks can be constructed and tested quantitatively against empirical data. Insofar as these models account well for observed dependent variables, this will facilitate the analysis of underlying mental and physical processes, leading to new predictions about them. Also, the models' failures can guide improvements to the theory's assumptions. Through this activity, cumulative scientific progress is more likely than if an informal piecemeal approach to theorising were taken.

Given these considerations, this paper outlines a unified computational theory, executive-process interactive control (EPIC), which has been formulated for modelling human multiple-task performance (Kieras \& Meyer, 1997; Meyer \& Kieras, 1997a, b, 1999). Here we describe how models based on EPIC can help answer fundamental questions about ageing and cognition. Two major phenomena, age-related slowing and reduced working memory, will be discussed specifically for this purpose. With respect to these phenomena, it will be shown that EPIC yields precise analytic accounts of ageing effects on various components of information processing. By taking the essence of these accounts seriously, a clearer and more accurate picture of cognitive ageing may be developed, and promising directions for future research on ageing and cognition may be identified. Also, novel perspectives on issues raised by other papers in this issue may be reached.

\section{THE EPIC ARCHITECTURE}

The architecture of EPIC extends previous theories about the structures and functions of the human information-processing system (e.g., Anderson, 1983; Card, Moran, \& Newell, 1983; Newell, 1990). With computational models based on EPIC, interactions among perceptual, cognitive, and motor processes can be described precisely in terms of executive control and task scheduling strategies. Thus, EPIC models are potentially well suited for characterising how speed of processing, working-memory capacity, dual-task performance, and other cognitive abilities change with age. 


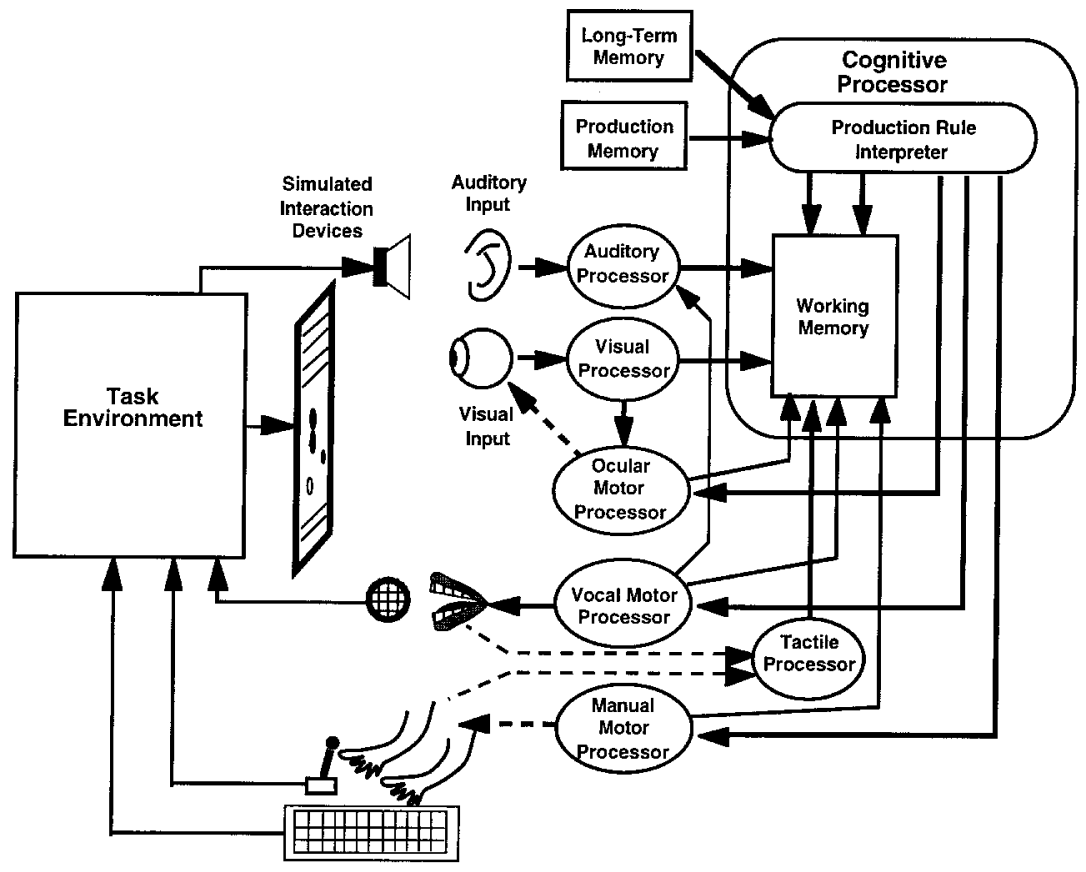

Figure 1. Overview of the EPIC architecture (adapted from Kieras, Meyer, Mueller, \& Seymour, 1999).

\section{Architectural components}

EPIC has a cognitive processor with a production-rule interpreter and working memory (WM) connected to modality-specific sensors, perceptual processors, motor processors, and effectors (Figure 1). These components constitute EPIC's "hardware" and operate in parallel with each other. The perceptual and motor processors serve as limited-capacity input and output channels. We model task performance by programming the cognitive processor with production rules that manipulate the contents of WM to make decisions and produce responses to stimuli (e.g., see Appendix). Details of EPIC's perceptual and motor processors appear elsewhere (e.g., Kieras \& Meyer, 1997). For now, EPIC's WM and cognitive processor are especially relevant to models of cognitive ageing.

\section{Working memory}

EPIC's WM has several complementary parts (Kieras et al., 1999).

- Modal stores. Three parts of WM are the visual, auditory, and tactile 
stores that contain coded information from the modality-specific perceptual processors.

- Control store. Another part of WM is the control store. It contains (1) goals, which appear in the conditions of production rules that help perform particular tasks, (2) steps, which cause rules to fire in specified sequences, (3) strategy notes, which enable or disable rules for alternative task strategies, and (4) status notes, which indicate the current states of various processes.

- Tag store. The tag store contains labels that assign specific roles to modal-store items. For example, such a label might designate an object in visual WM to be "the stimulus".

- Storage capacity. Items in the various parts of WM may decay after random amounts of time unless they are refreshed. However, there are no preset limits on the numbers of stored items. Thus, the capacity of EPIC's WM depends on the decay times and refresh rates during task performance.

\section{Cognitive processor}

EPIC's cognitive processor operates in cycles. On each cycle, the conditions of all rules in procedural memory are tested, and the actions of all rules whose conditions match the contents of WM are executed. We assume that for young adults, the mean time taken by a cognitiveprocessor cycle is $50 \mathrm{~ms}$, in accord with periodicities of human information processing (Kristofferson, 1967).

In EPIC, the cognitive-processor cycle time does not depend on how many rule conditions have to be tested or how many actions have to be executed, nor is there a set limit on how many rules can be applied during each cycle. Thus, EPIC has no cognitive hardware decision or response-selection bottleneck. This contrasts with the classic responseselection bottleneck hypothesis (Pashler, 1994), which assumes that if two choice-reaction tasks have to be performed concurrently, then response selection for one task must wait until response selection for the other task has finished.

EPIC's unlimited parallel application of production rules helps avoid the vagueness and circularity that plague resource and single-channel theories (cf. Allport, 1987). This is crucial for research on cognitive ageing. By tentatively assuming ample cognitive processing capacity, we are led to take careful account of limits in peripheral perceptual-motor mechanisms, which can cause performance decrements that might otherwise be misattributed to immutable cognitive decision or response-selection bottlenecks. Also, because EPIC has no such bottlenecks, it strongly encourages understanding human performance in terms of adaptive execu- 
tive control and flexible task strategies, to which studies of cognitive ageing should devote due consideration.

\section{EPIC MODELLING OF COGNITIVE AGEING}

Using EPIC, performance by young and older adults in many tasks can be modelled. Given results from a particular task, two computational models - one that fits the young adults' data closely, and another that fits the older adults' data-may be formulated. ${ }^{1}$ By determining how the models must differ to fit all of the data, we can infer where and in what amounts cognitive ageing affects individual components of the adult information-processing system. Also, after formulating potentially veridical EPIC models, we can continue refining them and testing new predictions about additional effects of ageing that should be observable if the models are indeed worthy.

There are two types of components, hardware and software, wherein EPIC models might incorporate effects of cognitive ageing (Table 1). Hardware components are modules of the architecture that stay the same across task environments and implement various types of information processing. Software components are sets of task and executive production rules that instantiate procedural knowledge and change from one task to the next. Both the parameters of the hardware and the contents of the software might change with the age of the adults whose performance is being modelled. A major goal of our research is to discover what age-related changes are essential to include as part of EPIC models that account well for performance of important perceptual-motor and cognitive tasks over the life span. Not all of our discoveries will seem surprising in light of prior knowledge about cognitive ageing. Nevertheless, through the rigorous theoretical approach that EPIC enables, deeper insights into the effects of ageing on cognition may be achieved.

Of course, we also assume that some aspects of EPIC may stay the same for young and older adults. At present, these age-invariant aspects include the types of processing components in the architecture, the established connections among them, and their qualitative properties (e.g., stimulus feature coding, parallel production-rule firing, movement feature coding). This then raises issues about what other aspects of the hardware and software components are likely to change with age.

\footnotetext{
${ }^{1}$ Of course, many EPIC models will not fit the data closely for either age group. Because EPIC has limited "free" parameters, we can often reject models based on it when they are unveridical (Kieras, Meyer, Ballas, \& Lauber, 2000; Meyer \& Kieras, 1997a).
} 
TABLE 1

Components of EPIC models that incorporate potential effects of cognitive ageing

Type of component Locus of ageing effect

Hardware

Perceptual processors

Motor processors

Cognitive processor

Working memory

Skill-acquisition mechanisms

Software $\quad$ Task production rules

Executive production rules
Nature of age-related changes

Decreased acuity of sensory interfaces Increased stimulus detection times Increased stimulus identification times Increased movement-preparation times Increased movement-initiation times Increased movement-execution times Increased movement variability Increased feedback-transmission times Increased cycle times Decreased decay times Decreased efficiency of compiled rules Decreased rate of rule refinement

Decreased algorithmic efficiency Increased conservatism Increased number of rule steps Decreased algorithmic efficiency Increased conservatism Increased number of rule steps

\section{Potential ageing effects in EPIC's hardware}

EPIC's hardware includes its perceptual, cognitive, and motor processors. Models of young and older adults' performance may incorporate effects of ageing in each of these components.

Perceptual-processor parameters. For example, EPIC's perceptual processors implement stimulus detection and identification. Associated with them are parameters that determine their fidelity (e.g., retinal sensitivity) and duration (e.g., identification time). Close fits of EPIC models to empirical data from young and older adults could involve different parameter values, manifesting how perceptual processing changes with age.

Motor-processor parameters. Similarly, EPIC's motor processors implement movement preparation, initiation, and execution. Associated with them are parameters that determine their fidelity (e.g., spatial movement variability) and duration (e.g., movement-feature preparation times). Again, close fits of EPIC models to data from young and older adults could involve different parameter values manifesting how motor processing changes with age. 
Working-memory parameters. The capacity of WM in EPIC is limited because stored items may decay unless they are refreshed periodically. Consequently, EPIC models of performance may incorporate effects of ageing on WM through shorter decay times and/or slower refresh rates. We would attribute shorter decay times to changes in underlying hardware, whereas slower refresh rates could be attributable to changes in either the hardware or software used for the refreshing processes.

Cognitive-processor parameters. The rate of processing in EPIC is constrained by the cognitive processor's mean cycle time. For young adults, we assume that this parameter equals $50 \mathrm{~ms}$. Our assumption is supported by both behavioural and psychophysiological data (e.g., Kristofferson, 1967). It conforms well with the mean period between zero crossings in the brain's alpha rhythm, which equals about $50 \mathrm{~ms}$ for young adults and correlates positively with their mean simple RTs (Callaway \& Yeager, 1960; Surwillo, 1963; Woodruff, 1975). It appears that alpha-rhythm zero crossings perhaps correspond to the onsets of cognitive-processor cycles.

In contrast, for older adults around 70 years of age, the mean zerocrossing period of the alpha rhythm is about $10-15 \%$ longer than for young adults (Marsh \& Thompson, 1977; Obrist \& Busse, 1965; Surwillo, 1963), and older adults' mean simple RTs are also about $10-15 \%$ longer (Cerella, 1985; Somberg \& Salthouse, 1982). These results lead us to make the following strong but at least somewhat plausible assumption: In EPIC models for older adults (circa 70 years of age), the mean cognitiveprocessor cycle time should be set to $56.5 \mathrm{~ms}$, about $13 \%$ longer than the mean cycle time in models for young adults (circa 20 years of age). This assumption is consistent with Kail and Salthouse (1994), who claimed that ageing affects "a fundamental component of the architecture of human cognition" which functions like the CPU clock of a microcomputer whose "clock speed" determines the rate of information processing.

Our assumption also agrees with Madden (1992), who claimed that in visual word-recognition tasks, mean RTs increase by roughly 4-10 ms per decade of age. Under EPIC, such tasks usually require about 3-8 cognitive-processor cycles to be completed. Moreover, ageing would involve roughly a $1.3 \mathrm{~ms}$ increase per decade in the mean cycle time. The latter factor, multiplied by 3-8 cycles, yields a range close to Madden's 4-10 ms per decade.

Furthermore, another key parameter that presumably mediates RTs and age-related slowing under EPIC is the number of cycles taken to complete a task, which depends on what production rules are used for task performance (Kieras \& Meyer, 2000). Insofar as older adults use less efficient rules and so take more cognitive-processor cycles than young adults, age-related RT differences may be larger than if only the mean 
time per cycle differs between groups. ${ }^{2}$ Such inefficiency might occur either because older adults prefer more conservative performance strategies (Botwinick, 1966), or because their rate of skill acquisition is lower than that of young adults (Strayer \& Kramer, 1994).

Skill-acquisition parameters. Currently, EPIC has no mechanisms of skill acquisition. However, we plan to implement them soon (Kieras et al., 2000), and this may help assess the extent to which older adults learn new procedures less quickly than young adults do.

\section{Potential ageing effects in EPIC's software}

There are two ways that effects of ageing might be incorporated in EPIC's software.

Task rule sets. Older adults may use less efficient sets of production rules for individual tasks. When this happens, especially salient slowing of performance should result. By fitting EPIC models to RT data, it is possible to quantify how much age-related slowing stems from such software differences above and beyond increases in the mean cognitive-processor cycle time.

Executive rule sets. Also relevant are potential ageing effects in executive production rules, which coordinate operations during concurrent tasks. Like task rules, the executive rules of older adults may be less efficient than those of the young (Mayr \& Kliegl, 1993). We can assess this possibility precisely by formulating EPIC models of dual-task performance for each age group. As a result, the extent to which older adults have impaired time-sharing abilities can be quantified.

\section{APPLICATION OF EPIC TO DUAL-TASK PERFORMANCE AND COGNITIVE AGEING}

To illustrate how fundamental questions about cognitive ageing may be answered on the basis of EPIC, we (Glass et al., 2000; Meyer \& Kieras, $1997 \mathrm{a}$, b) have formulated computational models of performance by young and older adults in a basic dual-task paradigm, the psychological

\footnotetext{
${ }^{2} \mathrm{An}$ inefficient set of production rules is one that takes more than the minimum number of algorithmic steps (and cognitive-processor cycles) required to perform a task properly. The extent to which a rule set is more or less efficient depends on the content and organisation of the rules' conditions and actions. If the conditions and actions are not configured optimally, then a rule set will fail to exploit the full parallel-processing capabilities of EPIC's cognitive processor (Kieras et al., 2000).
} 
refractory period (PRP) procedure. From doing so, we learn more about the sources of age-related slowing, and we show that older adults have better preserved time-sharing abilities than has sometimes been claimed before (cf. Allen, Smith, Vires-Collins, \& Sperry, 1998; Craik \& Byrd, 1982; Hartley \& Little, 1999).

\section{PRP procedure}

On each trial of the PRP procedure, a primary Task 1 stimulus is followed by a secondary Task 2 stimulus with a short (e.g., $\leqslant 1 \mathrm{sec}$ ) stimulus-onset asynchrony (SOA). Participants have to give Task 1 higher priority, and they are encouraged to make the Task 1 response first. RTs and response accuracy are measured as a function of the SOA and other task factors. The difference between mean Task 2 RTs at the shortest and longest SOAs is called the PRP effect. Because shorter SOAs typically yield longer Task 2 RTs, the PRP effect has been interpreted as a measure of interference caused by limited processing capacity in dual-task performance (Pashler, 1994).

\section{PRP effects in young and older adults}

Glass et al. (2000) measured PRP effects in young (age $=18-26$ years) and older (age $=60-70$ years) adults who performed an auditory-manual primary task and an "easy" or "hard" visual-manual secondary task. Task 1 involved two alternative stimulus-response (S-R) pairs and required keypresses with left-hand fingers to tones. Task 2 required keypresses with right-hand fingers to digits. For the easy and hard Task 2 , respectively, there were two and eight alternative S-R pairs, which affected the difficulty of response selection in Task 2 (Schumacher et al., 1999).

For young adults, Glass et al. (2000, Exp. 1) found that mean Task 1 RTs were short and not affected reliably by the SOA (Figure 2a). The young adult's mean Task 2 RTs increased as the SOA decreased. There was also a Task 2 difficulty effect, which interacted reliably with the SOA; the difference between mean RTs for the hard and easy Task 2 decreased as the SOA decreased.

For older adults, mean Task 1 RTs were longer than those of young adults (490 vs. $300 \mathrm{~ms}$ ), but SOA affected them relatively little (Figure 2b). Also, mean Task 2 RTs of older adults were longer and more affected by SOA, yielding greater PRP effects than those of young adults ( 300 vs. $130 \mathrm{~ms}$ for the easy Task 2, and 250 vs. $85 \mathrm{~ms}$ for the hard Task 2). The older adults' PRP effects were larger when divided by their mean Task 2 RTs at the longest SOA, which yields a normalised measure of dual-task interference (i.e., for the easy and hard Task 2, older adults' 
(a)

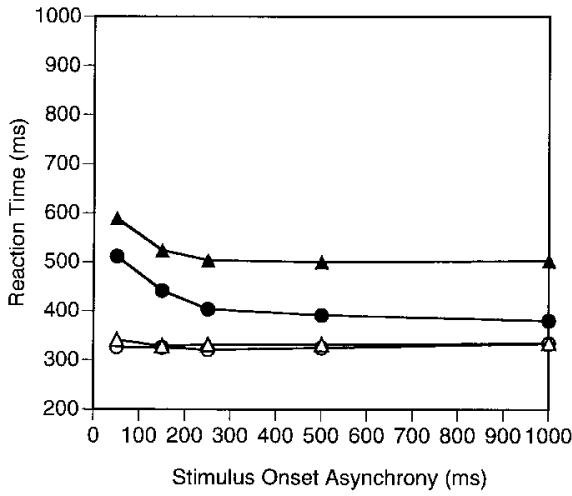

(b)

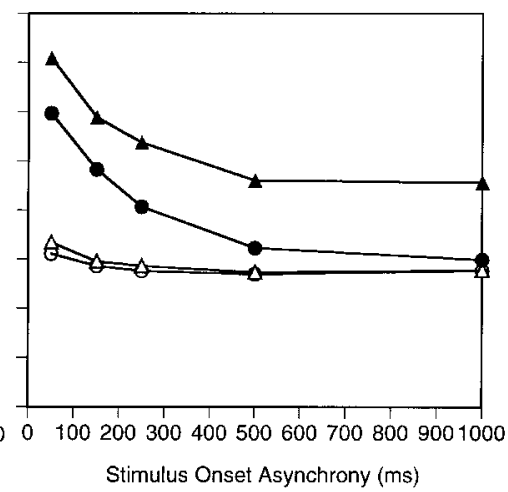

$$
\begin{aligned}
& - \text { Task } 1 \text { (Easy Task 2) } \\
& -\triangle \text { Task } 1 \text { (Hard Task 2) } \\
& \rightarrow-\text { Easy Task } 2 \\
& \neg \text { Hard Task 2 }
\end{aligned}
$$

Figure 2. Mean reaction times (RTs) of young (a) and older (b) adults for Tasks 1 and 2 as a function of Task 2 difficulty (easy or hard) and stimulus onset asynchrony (SOA) in Glass et al. (2000, Exp. 1).

normalised dual-task interference $=0.60$ and 0.38 ; young adults' normalised dual-task interference $=0.34$ and 0.17 ).

In other respects, however, mean RTs for the two age groups were similar. $^{3}$ Most important, older as well as young adults had reliable interactions between the SOA and task-difficulty effects on mean Task 2 RTs. As SOA decreased, the difficulty effect decreased by about $50 \mathrm{~ms}$ regardless of age. This is crucial for interpreting the overall pattern of results from the two age groups.

\section{Theoretical interpretation of RT data}

At first glance, Glass et al.'s (2000) results might be interpreted as showing that older adults have impaired time-sharing ability. This seems

\footnotetext{
${ }^{3}$ For both age groups, error rates were low $(<5 \%)$ and revealed no major speed-accuracy tradeoffs. Like young adults, older adults produced extremely few $(<0.1 \%)$ out-of-order responses in which, contrary to instructions of the PRP procedure, a Task 2 response occurred before the accompanying Task 1 response. Ageing did not disrupt older adults' control over the serial order of their responses.
} 
consistent with their PRP effects and normalised dual-task interference, which were larger than those of young adults. Indeed, such enlarged costs have led some researchers to conclude that older adults are seriously hampered in dual-task performance, perhaps because of an "elongated" response-selection bottleneck (e.g., Allen et al., 1998).

Nevertheless, further aspects of Glass et al.'s (2000) results suggest otherwise. Older adults had a significant underadditive interaction between the effects of SOA and task difficulty on mean Task 2 RTs, just like the young adults. This interaction may stem from concurrent response-selection processes for Tasks 1 and 2 (Meyer \& Kieras, 1997a, b). If so, then perhaps older adults can time-share about as well as the young, despite age-related slowing in the performance of each task. To test this hypothesis further, we have used EPIC to formulate adaptive executive-control (AEC) models that fit the data from both young and older adults in Glass et al.'s (2000) study.

\section{Adaptive executive-control models}

According to our AEC models, dual-task performance progresses through stages of stimulus identification, response selection, and movement production (Figure 3). We assume that an executive process coordinates this progress by postponing some Task 2 processes until Task 1 has finished, satisfying priorities of the PRP procedure. The functions of the executive process include: (a) enabling Task 1 and Task 2 processes to start on each trial; (b) specifying a Task 2 lockout point; (c) specifying a Task 1 unlocking event; (d) waiting for the Task 1 unlocking event to occur; and (e) unlocking the Task 2 processes so that they may be completed. $^{4}$

Task 2 lockout points. By definition, the Task 2 lockout point occurs during the course of Task 2. When it is reached, further processing for Task 2 is postponed until Task 1 is "completed". Our AEC models have three possible lockout points (Figure 3, lower small ovals), located respectively before the onsets of stimulus identification, response selection, and movement production for Task 2. After short SOAs, Task 2 processes would overlap more or less with Task 1 processes, depending on whether the executive process uses a pre-movement-production, pre-responseselection, or pre-stimulus-identification lockout point.

\footnotetext{
${ }^{4}$ Representative sets of production rules that illustrate how executive and task processes have been implemented with EPIC for the PRP procedure appear in Meyer and Kieras (1997a).
} 
Task 1 Processes

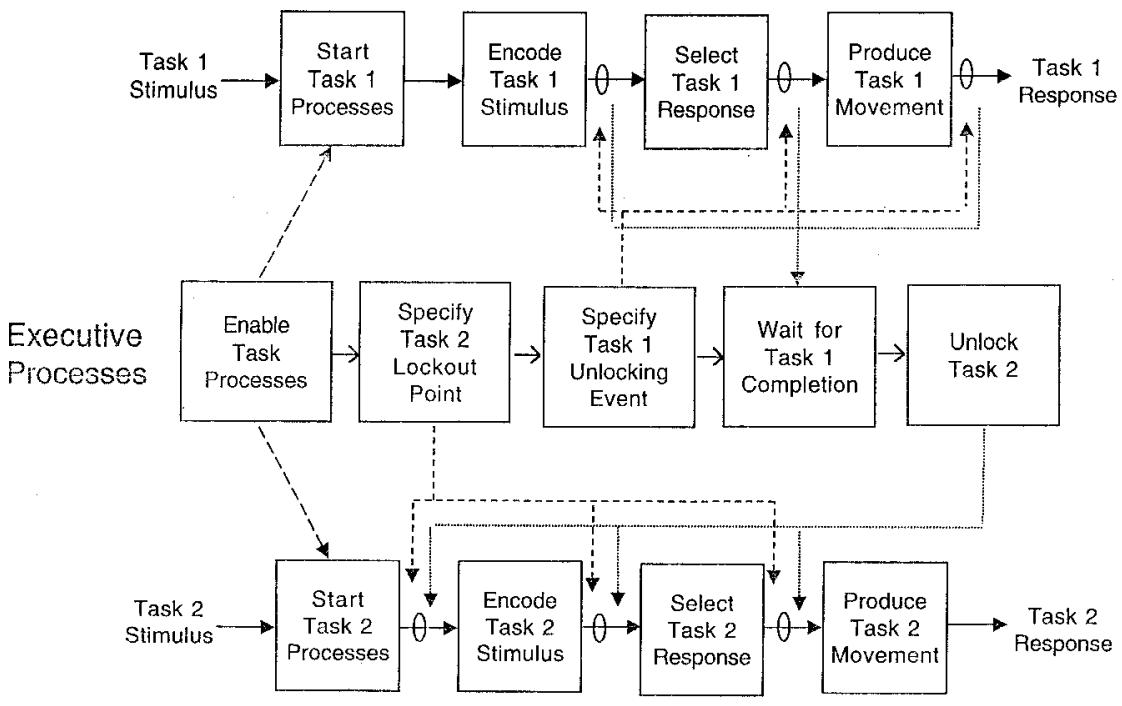

Task 2 Processes

Figure 3. Component processes of adaptive executive-control (AEC) models for flexible scheduling of dual-task performance in the psychological refractory period (PRP) procedure. The top, middle, and bottom rows of the diagram depict Task 1, executive, and Task 2 processes, respectively. Downward arrows from the executive process that specifies the Task 2 lockout points indicate alternative sites (lower small ovals) at which progress on Task 2 may be suspended until Task 1 is deemed to be "completed". Upward arrows from the executive process that specifies the Task 1 unlocking events indicate alternative sites (upper small ovals) at which Task 1 processes may signal the executive processes to treat Task 1 as "completed" and to resume Task 2 by unlocking it. (From "Concurrent response-selection processes in dual-task performance: Evidence for adaptive executive control over task-scheduling strategies", E.H. Schumacher, E.J. Lauber, J.M. Glass, E.L. Zurbriggen, L. Gmeindl, D.E. Kieras, and D.E. Meyer, 1999, Journal of Experimental Psychology: Human Perception and Performance, 25, p. 793. Copyright 1999 by the American Psychological Association. Reprinted with permission of the author.)

Task 1 unlocking events. The overlap between Task 1 and Task 2 processes also depends on which Task 1 unlocking event is used. This event determines when Task 1 is "completed", allowing the executive process to resume processing for Task 2. There are three possible Task 1 unlocking events (Figure 3, upper small ovals), which occur after stimulus identification, response selection, and movement production for Task 1. After short SOAs, Task 2 processes would overlap more or less with Task 1 processes, depending on whether the executive process uses a post-stimulus-identification, post-response-selection, or post-movement-production unlocking event. 
Specific AEC models. Overall, our AEC models include various specific cases. For each possible combination of the Task 2 lockout point and Task 1 unlocking event, there is a set of executive production rules that implements them. Consequently, some AEC models can mimic a response-selection bottleneck with a post-stimulus-identification/preresponse-selection lockout point for Task 2 (cf. Pashler, 1994). This constitutes cautious task scheduling because it precludes much overlap between stages of processing for the two tasks, thereby decreasing the likelihood that responses occur out of order. Other AEC models may mimic a movement-initiation bottleneck with a post-response-selection/ pre-movement-production lockout point for Task 2 (cf. Keele, 1973). This constitutes daring task scheduling because it allows more overlap between processing stages, increasing the likelihood of out-of-order responses. Task instructions, perceptual-motor requirements, prior practice, and cognitive style may influence which type of scheduling is used.

\section{Young and older adults' AEC models}

We have identified two AEC models that account respectively for quantitative results from the young and older adults in Glass et al. (2000).

TABLE 2

Mean values of parameters in the adaptive executive-control models of dual-task performance for young and older adults in Glass et al. (2000)

\begin{tabular}{|c|c|c|c|c|c|c|c|}
\hline \multirow[b]{2}{*}{ Component } & \multirow[b]{2}{*}{ Parameter type } & \multicolumn{2}{|c|}{ Task 1} & \multicolumn{2}{|c|}{ Easy Task 2} & \multicolumn{2}{|c|}{ Hard Task 2} \\
\hline & & Young & Old & Young & Old & Young & Old \\
\hline $\begin{array}{l}\text { Perceptual } \\
\text { processors }\end{array}$ & Stimulus identification time & 120 & 254 & 121 & 205 & 121 & 205 \\
\hline $\begin{array}{l}\text { Motor } \\
\text { processors }\end{array}$ & $\begin{array}{l}\text { Number of movement features } \\
\text { Movement production time }\end{array}$ & s $\begin{array}{r}1 \\
100\end{array}$ & $\begin{array}{r}1 \\
113\end{array}$ & $\begin{array}{r}2 \\
150\end{array}$ & $\begin{array}{r}2 \\
169\end{array}$ & $\begin{array}{r}2 \\
150\end{array}$ & $\begin{array}{r}2 \\
169\end{array}$ \\
\hline $\begin{array}{l}\text { Cognitive } \\
\text { processor }\end{array}$ & Cycle time & 50 & 56.5 & 50 & 56.5 & 50 & 56.5 \\
\hline Task rules & $\begin{array}{l}\text { Number of selection steps } \\
\text { Response-selection time }\end{array}$ & $\begin{array}{r}1.5 \\
75\end{array}$ & $\begin{array}{r}1.5 \\
85\end{array}$ & $\begin{array}{r}1.5 \\
75\end{array}$ & $\begin{array}{r}1.5 \\
85\end{array}$ & $\begin{array}{r}4.0 \\
200\end{array}$ & $\begin{array}{r}4.5 \\
254\end{array}$ \\
\hline $\begin{array}{l}\text { Executive } \\
\text { rules }\end{array}$ & $\begin{array}{l}\text { Task } 1 \text { unlocking event } \\
\text { Task } 2 \text { lockout point } \\
\text { Unlocking duration }\end{array}$ & PME & PME & $\begin{array}{r}\text { PRS } \\
80\end{array}$ & $\begin{array}{r}\text { PRS } \\
224\end{array}$ & $\begin{array}{r}\text { PRS } \\
80\end{array}$ & $\begin{array}{r}\text { PRS } \\
224\end{array}$ \\
\hline
\end{tabular}

$\mathrm{PME}=$ pre-movement-execution in Task $1 ; \mathrm{PRS}=$ post-response-selection in Task 2. 
Table 2 shows the similarities and differences between these models in terms of their hardware parameters, task processes, and executive processes. $^{5}$

Differences between hardware parameters. There are several age-related differences between the hardware parameters of the young and older adults' models. Consistent with our previous assumptions, the mean cognitive-processor cycle time is $13 \%$ longer $(56.5 \mathrm{vs} .50 \mathrm{~ms}$ ) for the older adults. ${ }^{6}$ Supplementing this increase, stimulus identification by the visual and auditory perceptual processors take about $70 \%$ and $110 \%$ longer, respectively, in the young and older adults' models. That these latter increases are so large may be attributable at least partly to deficits from ageing in peripheral sensory mechanisms (Glass, 2000; Scialfa, 2000). For example, ageing in parts of the inner ear could cause the identification and discrimination of tone stimuli to be especially slow (cf. van Boxtel et al., 2000).

Differences between task processes. Also, to fit Glass et al.'s (2000) data, the older adults' AEC model uses less efficient rules for response selection in the hard Task 2, which cause its response-selection times to be longer than those of the young adults' model. ${ }^{7}$ This feature is essential because the difficulty effect on older adults' mean Task 2 RTs at the longest SOA exceeded what could stem simply from their $13 \%$ longer mean cognitive-processor cycle times.

Differences between executive processes. Furthermore, there is one difference between the executive processes of the two models that has been incorporated to fit the data in Figure 2. It involves the unlocking duration (i.e., the amount of time taken to resume Task 2 after the Task 1 unlocking event occurs). The older adults' model has executive processes that take almost three times longer to unlock Task 2 than do those of the young adults' model. This may be needed here because older adults are sometimes rather cautious in avoiding out-of-order Task 2 responses. However, their unlocking durations are not always much longer than young adults'; instead, they appear to depend on relevant contextual factors (Glass et al., 2000). Such context dependence implies that age-related

\footnotetext{
${ }^{5}$ For more details about how we arrived at these models and their parameter values, see Glass et al. (2000).

${ }^{6}$ Models in which the mean cognitive-processor cycle time substantially exceeded $56.5 \mathrm{~ms}$ for the older adults did not fit their mean RTs very well (Glass et al., 2000).

${ }^{7}$ Examples of how such inefficiency might be embodied in sets of task production rules appear in Meyer and Kieras (1997a).
} 
changes in the unlocking durations probably stem from adjustable software characteristics rather than chronic hardware deficiencies.

Similarities between executive processes. Most important, in two major respects, the executive processes of the present older adults' model are essentially like those of the young adults' model. First, both models involve a post-response-selection Task 2 lockout point, which enables concurrent response selection for Tasks 1 and 2, unlike what would happen if there were a response-selection bottleneck. Second, both models involve a pre-movement-execution Task 1 unlocking event, which enables unlocking of Task 2 to start relatively early. These features are hallmarks of "daring" task scheduling, and they suggest that older adults have well preserved time-sharing abilities.

Fits of the AEC models to RT data. Supporting this latter suggestion, Figure 4 shows fits between empirical mean RTs from Glass et al. (2000, Exp. 1) and theoretical mean RTs from the young and older adults' AEC models. Here we focus on RTs at the shortest and longest SOAs, which embody the PRP and task difficulty effects for the two age groups.

(a)

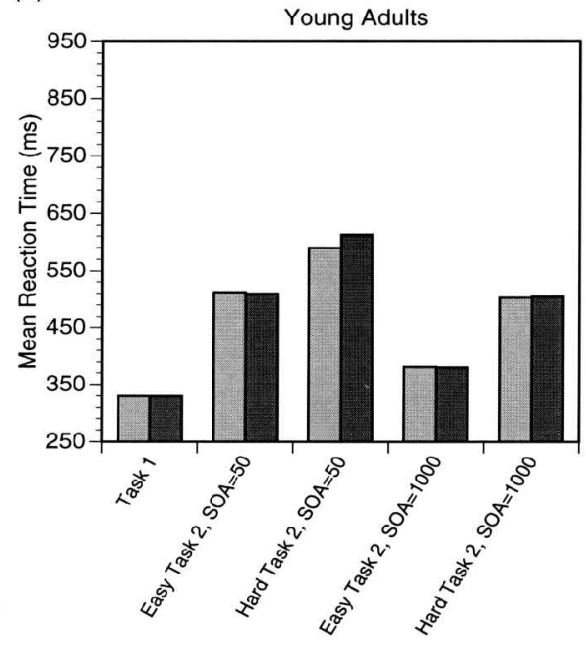

(b)
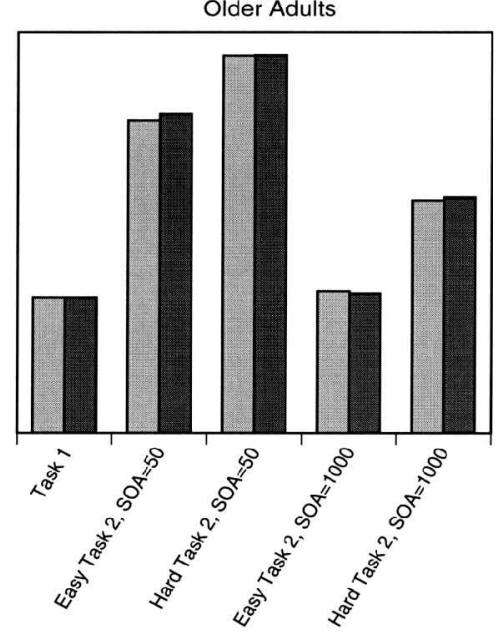

Empirical RTs

Theoretical RTs

Figure 4. Theoretical mean reaction times (RTs) from best-fitting adaptive-executive control (AEC) models paired with corresponding empirical mean reaction times from Glass et al. (2000, Exp. 1). (a) RTs for young adults. (b) RTs for older adults. 
Clearly, the theoretical RTs approximate the empirical RTs closely, accounting well for the magnitudes of observed factor effects on them.

\section{Theoretical conclusions}

From this application of EPIC to cognitive ageing and dual-task performance, several theoretical conclusions follow. First, we conclude that computational modelling based on a principled architecture helps resolve ambiguities created by merely evaluating empirical data qualitatively. Second, we conclude that under conditions like Glass et al.'s (2000), cognitive ageing has selective effects on hardware and software components whose proportional magnitudes are task-dependent and differ across various stages of processing. Third, the good fits of our AEC models suggest that, in some dual-task paradigms, older adults exhibit well-preserved time-sharing abilities. ${ }^{8}$

\section{APPLICATION OF EPIC TO VERBAL WORKING MEMORY AND COGNITIVE AGEING}

A second application of EPIC involves verbal working memory (WM) and cognitive ageing. Here again, our work distinguishes precisely between contributions by hardware and software components of processing. To appreciate the importance of this, more background is in order.

Some evidence shows that older adults perform less well than young adults in tasks that impose heavy loads on WM (Craik \& Jennings, 1992). This decline has been revealed by complex memory-span tasks in which participants must integrate and retain successive bits of information (e.g., words, numbers, pictures) while executing other operations (e.g., sentence comprehension, arithmetic calculations) related to the input. During such tasks, final serial recall of the retained information has sometimes been much lower in older adults, and older adults' relative declines have increased with task complexity (e.g., Foos, 1989; Gick, Craik, \& Morris, 1988; Park et al., 1996; Wingfield, Stine, Lahar, \& Aberdeen, 1988).

\footnotetext{
${ }^{8}$ This last conclusion is not contradicted by the relatively long unlocking durations for Task 2 of the older adults' AEC model in Table 2. As mentioned previously, older adults do not always take especially long times to unlock secondary tasks of the PRP procedure, and their unlocking durations appear to be adjustable through adaptive executive control (Glass et al., 2000). Also consistent with this conclusion are the quite small age-related effects on switching-time costs that have been observed in some studies of task switching (e.g., Brinley, 1965; Mayr \& Kliegl, 2000).
} 
Nevertheless, some aspects of WM-as revealed by putatively "simpler" tasks - appear rather well-preserved with age. A large recency effect on immediate free recall occurs for older adults (Craik, 1968; Raymond, 1971). In the Brown-Peterson procedure, the memory traces of older adults are about as durable as young adults' (Charness, 1981; Puckett \& Stockburger, 1988; Talland, 1967). Also, older adults often have very small (e.g., $\leqslant 5 \%$ ) deficits in forward memory span (Botwinick \& Storandt, 1974; Bromley, 1958; Clark \& Knowles, 1973). One interpretation of these results is that the storage component of verbal WM remains intact for older adults, but their executive processes that update and manipulate the contents of WM in more complex tasks may be deficient (D’Esposito \& Postle, 1999; Salthouse, Babcock, \& Shaw, 1991; Smith \& Jonides, 1999).

Yet other results raise doubts about this interpretation. From a metaanalysis of studies that involved various WM tasks, Babcock \& Salthouse (1990) found multiple cases in which older adults performed almost as well on complex tasks as on simpler ones, and there were only small age-related differences (e.g., Baddeley, Logie, Bressi, Della Salla, \& Spinnler, 1986; Burke \& Yee, 1984; Dobbs \& Rule, 1989; Ferris, Crook, Clark, McCarthy, \& Rae, 1980; Hooper, Hooper, \& Colbert, 1984; Light \& Anderson, 1985). These prominent "islands of preservation" raise intriguing issues about when and in what ways WM becomes impaired with age.

To help resolve such issues, we have formulated EPIC models of agerelated effects on coding, storage, maintenance, updating, manipulation, and coordinative operations in verbal WM. For example, one of our models describes performance by young and older adults in basic serial memory-span tasks, which are prototypical WM paradigms (Baddeley, 1986). This description extends past research that has modelled agerelated declines of WM (e.g., Byrne, 1998; Maylor, Vousden, \& Brown, 1999). From doing so, more may be learned about the effects of ageing on WM functions.

\section{Basic serial memory-span tasks}

The memory-span tasks with which we deal here are basic ones as used in the WAIS-R battery (Wechsler, 1981) and many studies of verbal WM (e.g., Baddeley, Thomson, \& Buchanan, 1975; Drewnowski, 1980; Longoni, Richardson, \& Aiello, 1993; Standing, Bond, Smith, \& Isely, 1980). On each trial, a sequence of verbal items (digits, letters, words, or pseudowords) is presented auditorily at a constant moderate rate (1-2s per item). At the end of the sequence, which typically contains two to ten items, there is a recall signal, and the participant tries to recall the items either in their original forward order, or in backward order. The 
presented items are sampled randomly from a small set whose members occur repeatedly across trials but no more than once per trial. ${ }^{9}$

\section{An EPIC model for verbal serial memory span}

Our model has some similarities to the phonological-loop model of Baddeley (1986) and others (e.g., Schweickert \& Boruff, 1986). We assume that when a sequence of items is presented auditorily, the auditory perceptual processor codes each item as a packet of phonological features with pointers that let the packet be linked to ones for preceding and following items. The coded items are stored in auditory WM, where they decay after some time. Such coding and storage are also assumed to occur when the vocal motor processor produces a sequence of items through covert articulation, which sends them to the auditory perceptual processor as if they had been presented auditorily. ${ }^{10}$ By having EPIC's cognitive processor pass stored items from auditory WM to the vocal motor processor repeatedly, a cyclic rehearsal process that maintains the items for final serial recall is implemented in our model (Kieras et al., 1999; Meyer, Mueller, Seymour, \& Kieras, 2000; Mueller, Seymour, Glass, Kieras, \& Meyer, 2000).

However, this implementation is not like an automatic tape loop that passively records and replays item sequences. Instead, we have found that the basic memory-span task requires much more than just "pure storage" (cf. D'Esposito \& Postle, 1999). To account for both forward and backward memory spans, the auditory perceptual processor, WM, and vocal motor processor must be controlled by intricate supraordinate executive and subordinate task processes, which interactively coordinate and accomplish the mental construction, storage, maintenance, and recall of presented item sequences. This is because processing of successive new items has to overlap in a complementary manner with continued cyclic rehearsal of prior stored items (Figure 5).

Chain-construction processes. As part of our model, there is a process that constructs an "add-chain" with new coded items from the external stimulus source (Figure 5, upper left). The add-chain construction process

\footnotetext{
${ }^{9}$ This procedure helps ensure that performance of the memory-span task is based on phonological codes in WM rather than graded levels of activation in long-term semantic memory.

${ }^{10}$ EPIC's vocal motor processor can produce either overt or covert utterances in response to commands from the cognitive processor, which provides symbolic information about the utterances' required style and content. In EPIC, overt and covert utterances are produced at essentially equivalent rates, consistent with reported empirical data (Landauer, 1962).
} 


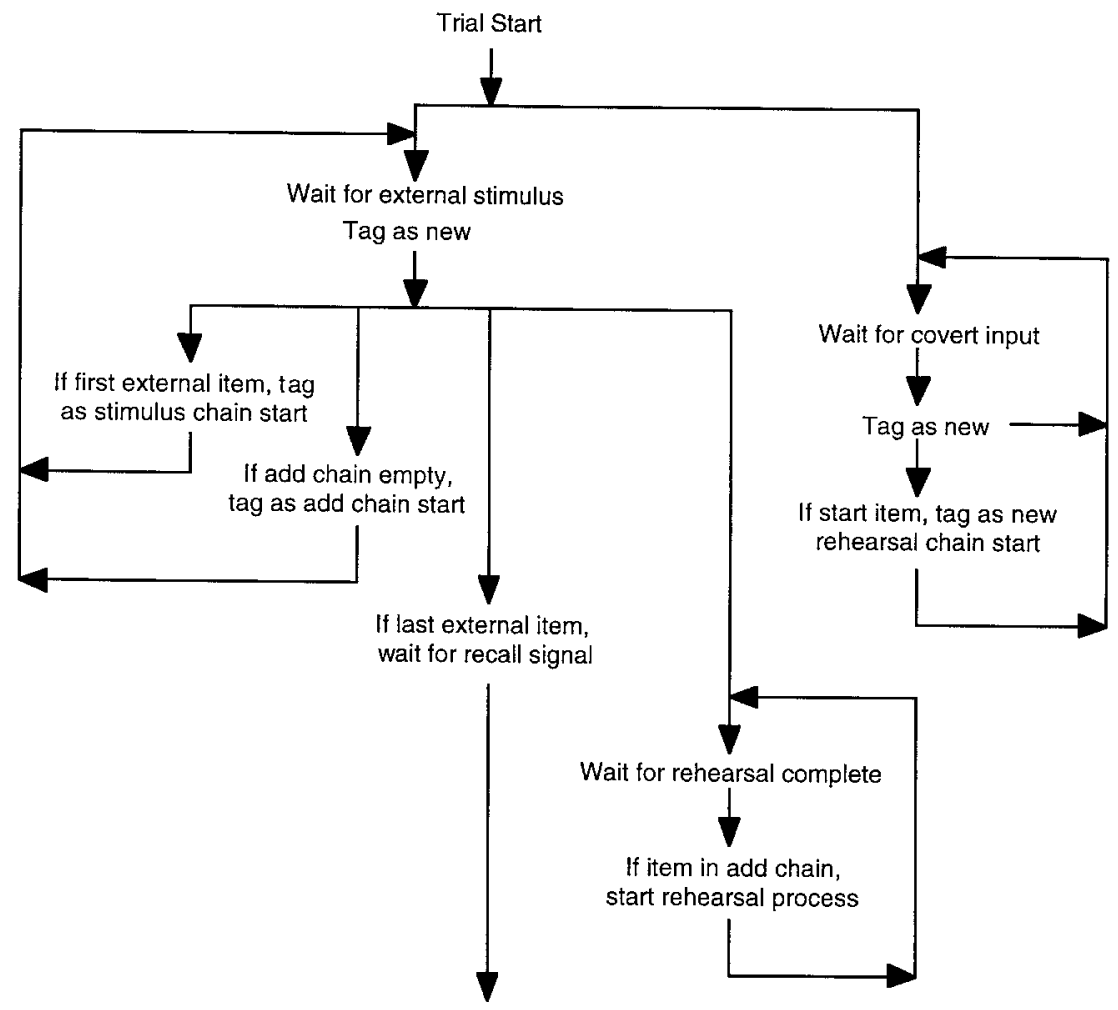

Wait for recall signal and rehearsal complete

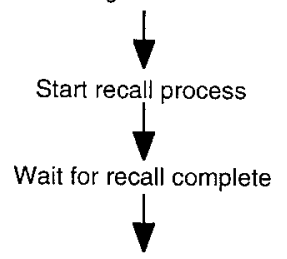

Terminate all threads

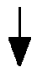

Trial done

Figure 5. Flowchart of supraordinate executive control and subordinate task processes (item chain-construction, rehearsal, and recall procedures) in the present EPIC model for performing the verbal serial memory-span task. (Adapted from Kieras et al., 1999.)

is implemented by production rules that wait for each item to arrive initially in auditory WM and then tag it as a "new" one for the add-chain. Another related process (Figure 5, upper right) constructs a "rehearsalchain" with covert verbal items produced by subvocal rehearsal. The 
rules of this rehearsal-chain construction process wait for each covert item and tag it as a "new" one to be included in the next cycle of rehearsal. During successive rehearsal cycles, multiple evolving chains of stored items are constructed. The most recent copy of the rehearsal chain and the current add-chain are used for the next rehearsal cycle.

Rehearsal process. The rehearsal process is implemented by another set of rules. A cycle of rehearsal starts whenever the first external stimulus item arrives in auditory WM, or a preceding rehearsal cycle has been completed and the current add-chain contains items that have not been rehearsed yet (Figure 5, middle right). Thereafter, the current rehearsal cycle proceeds as shown in Figure 6. Along its way, the pointers associated with individual items of the current rehearsal-chain and add-chain are used to determine the order of subvocalisation. For the next cycle of

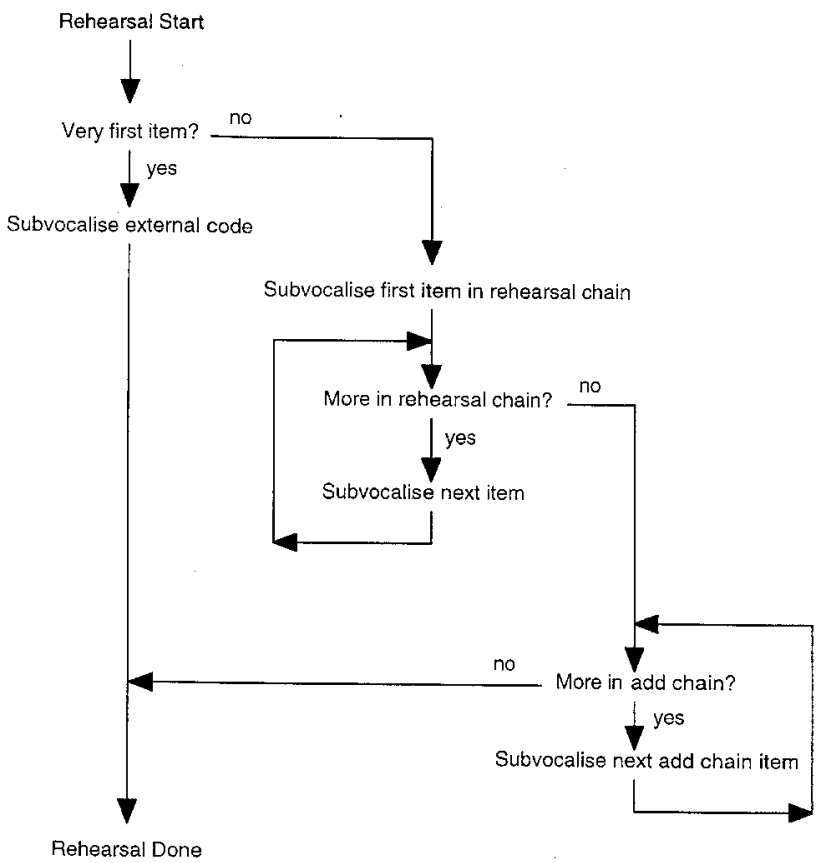

Figure 6. Steps in one cycle of the rehearsal process used by the present EPIC model for performing the verbal serial memory-span task. A rehearsal cycle includes consecutive phases that, when need be, subvocalise the first external stimulus item on a trial, subvocalise each item of the current rehearsal-chain in auditory working memory, and then subvocalise each item of the current add-chain. (Adapted from Kieras et al., 1999.) 
rehearsal, the chain-construction processes designate the new rehearsal chain in auditory WM, tagging its starting item as "new" so that it can be accessed when needed. Chains of items from previous cycles are tagged as "old" but remain in auditory WM, decaying haphazardly as time passes. $^{11}$

Recall process. The recall process starts after the last external stimulus item has been received, a recall signal has been detected, and the most recent rehearsal cycle has been completed. During recall, additional production rules enable attempts to vocalise every item in the last rehearsalchain. This entails having the cognitive processor send rehearsal-chain items one-by-one from auditory WM to the vocal motor processor for overt output, conforming insofar as possible to the required forward or backward order of recall. ${ }^{12}$ If serial-order pointers or phonological features for an item have decayed before its recall occurs, then the recall process makes sophisticated guesses about the item's identity. Errors in recall occur when these guesses are either incorrect or impossible to make.

Other ancillary assumptions. Finally, so our model is specified fully, it includes other ancillary assumptions: (1) No preset limit exists on the number of items in auditory WM. (2) Phonologically similar items have more features in common than do dissimilar items. (3) Individual phonological features and serial-order pointers decay according to independent, discrete, all-or-none stochastic processes. (4) The decay times have lognormal distributions with two parameters, the median $(M)$ and "spread" $(s)$ of the distribution. ${ }^{13}$ (5) The values of $M$ and $s$ may differ for phonological features and serial-order pointers. (6) These values also depend on whether the features and pointers come from external stimulus presentation or internal subvocal articulation.

\footnotetext{
${ }^{11} \mathrm{~A}$ difficulty caused by haphazard decay of items is that the rehearsal process may fail occasionally and unpredictably. Such failures can occur during a rehearsal cycle if an item in the current rehearsal-chain or add-chain disappears from auditory WM before it has been subvocalised. Graceful recovery and continuation after this requires intervention by appropriate executive control that is implemented as part of our model.

${ }^{12}$ When the memory-span task is performed with articulatory suppression during presentation of an item sequence (Baddeley, 1986), we assume that no subvocal rehearsal occurs, and our model's recall process bases its output instead on the initial stimulus-chain sent by the auditory perceptual processor to auditory WM (Kieras et al., 1999).

${ }^{13}$ The log-normal distribution is unimodal and positively skewed over the non-negative real numbers (Hastings \& Peacock, 1975). Distributions of real decay times presumably have these features. Parameterisation with $M$ and $s$ helps implement and interpret effects caused by changes in the log-normal distribution's central tendency and dispersion.
} 
Previous tests of the model. On the basis of these assumptions, we have tested our model by using it to account for data from studies that measured young adults' memory spans (e.g., Baddeley et al., 1975; Drewnowski, 1980; Longoni et al., 1993). These studies have shown that memory spans are affected by the numbers of items in the sequences, the items' articulatory durations, phonological similarity, serial position, and articulatory suppression. Our model has yielded close fits to percentages of correct recall and effects of these factors, using minimal "free" parameters. The model's successes suggest that it may help understand agerelated changes in verbal WM.

\section{Modelling of memory span in young and older adults}

Pursuing the latter prospect further, we have applied our EPIC model of memory span to analyse changes in verbal WM across the life span.

Gregoire and Van der Linden's study. For now, our analysis focuses on a study by Gregoire and Van der Linden (1997). They measured memory spans of adults from 20 to 80 years old with WAIS-R digit-span tests (Wechsler, 1981). Between 20 and 70 years of age, quite gradual declines occurred in both forward and backward memory spans, but the declines became steeper thereafter (Figure 7). Also, backward spans were less than forward spans, but they declined at about the same rate. Similar results have been reported by others (Burke \& Yee, 1984; Dobbs \& Rule, 1989; Ferris et al., 1980; Hooper et al., 1984; Light \& Anderson, 1985; Orsini et al., 1986; Park et al., 1996).

Theoretical account. Our EPIC model provides a theoretical account for these age-related changes of memory span. Simulated spans produced by the model closely approximate observed spans (Figure 7). For 20-70 years of age, the declines of forward and backward spans are well predicted by the gradual increase of the cognitive-processor cycle time assumed before (Table 2). The increase that yields a good fit to the data is about $1.3 \mathrm{~ms}$ per decade, rising from a mean of 50 to $56.5 \mathrm{~ms}$ over the 20 - to 70-year range. Thus, for this age range, there appears to be no change in verbal WM capacity other than what stems from modest cognitive slowing (cf. Salthouse, 1996).

However, according to our model, the steeper declines of memory spans from 70 to 80 years stem from one or more changes in other WM components. Such changes may involve (1) shorter decay times of phonological codes in WM, (2) longer speech production times of the vocal motor processor, or (3) decreased success rates of executive control 


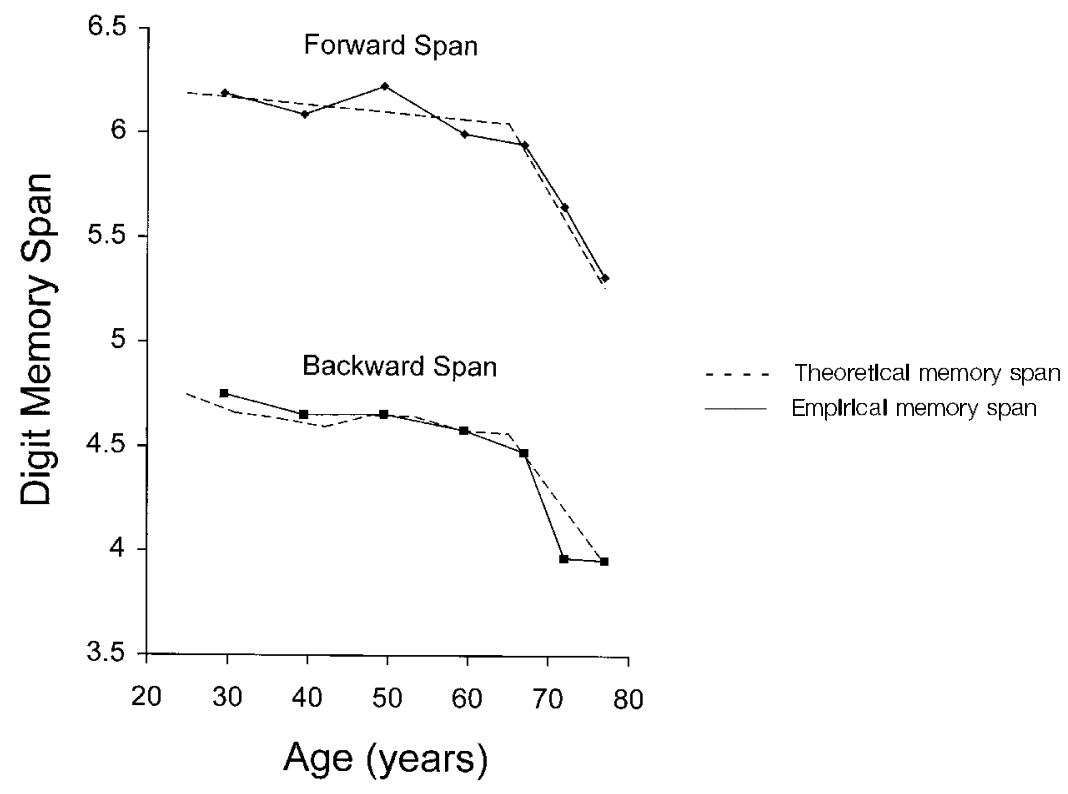

Figure 7. Theoretical memory spans from the present EPIC model compared to corresponding empirical memory spans as a function of age in Gregoire and Van der Linden (1997). Upper and lower pairs of curves show results for forward and backward memoryspan tasks, respectively. Over the 20- to 70-year age range, the changes in theoretical memory spans were obtained simply by increasing the mean cycle time of EPIC's cognitive processor by $1.3 \mathrm{~ms}$ per decade, starting with $50 \mathrm{~ms}$ at 20 years and reaching $56.5 \mathrm{~ms}$ at 70 years. Over the 70- to 80-year age range, additional adjustments in components of the model (Table 3) were made to account as best possible for steeper declines in the empirical memory spans. The empirical memory spans shown here have been recalculated from the original reported ones so that subgroups of adults having different levels of education contribute the same proportional amounts of data for each age group.

processes. ${ }^{14}$ Table 3 shows how large each such change would have to be by itself to account for the data over the $70-80$ year range.

Effects of old age on the model's parameters. From Table 3, we see that effects of old age on verbal WM may produce various percentages of change, depending on which component is involved. Relatively small $(15 \%)$ decreases of decay times may yield the steep declines of memory span from 70 to 80 years. Alternatively, these declines may stem from

\footnotetext{
${ }^{14}$ In this context, "success" means completing the trial without suffering any catastrophic disruptions during it.
} 
TABLE 3

Age-related changes in parameters of the EPIC model for serial memory spans from Gregoire and Van der Linden (1997)

\begin{tabular}{llll}
\hline Component & Parameter & Age & Value \\
\hline Cognitive processor & Mean cycle time & 20 & $50.0 \mathrm{~ms}$ \\
& & 70 & $56.5 \mathrm{~ms}$ \\
Auditory working memory & & 80 & $57.8 \mathrm{~ms}$ \\
& Median decay time & 20 & $4800 \mathrm{~ms}$ \\
Vocal motor processor & & 70 & $4800 \mathrm{~ms}$ \\
& & 80 & $4050 \mathrm{~ms}$ \\
Executive control process & & 20 & $250 \mathrm{~ms}$ \\
& & 70 & $250 \mathrm{~ms}$ \\
& & 80 & $360 \mathrm{~ms}$ \\
& & 20 & $100 \%$ \\
& & 70 & $100 \%$ \\
\hline
\end{tabular}

larger $(\geqslant 40 \%)$ increases in speech production times, or intermediate $(25 \%)$ decreases in the success rates of executive processes. ${ }^{15}$

\section{Theoretical conclusions}

Our application of EPIC to verbal WM suggests that across much of the life span, the components of WM remain well-preserved. We have discovered that basic memory-span tasks require intricate executive control to be performed successfully; they are not merely "pure storage" tasks. Yet before adults reach about 70 years old, their memory spans are almost as great as those of 20-year-olds. Thus, unlike what some researchers have suggested, it appears to us that adults do not lose much capacity for "coordinative" information processing until relatively late in life (cf. Mayr \& Kliegl, 1993). ${ }^{16}$ This insight is enabled because EPIC allows the

\footnotetext{
${ }^{15}$ Apparent declines in verbal WM may also stem from impairments of peripheral hearing mechanisms (van Boxtel et al., 2000). Such impairments could have especially large deleterious effects on performance of complex WM tasks, because these tasks often entail elaborate and unfamiliar sequences of auditory stimuli.

${ }^{16}$ Some readers may wonder whether measures of basic forward and backward memory spans are sensitive to large increases in the durations of executive processes that mediate them (Steven Keele, personal communication). The answer is "yes". For example, if the times taken by the executive processes of our EPIC model to perform the memory-span tasks had been lengthened by much more than the age-related increase of $13 \%$ in the mean cognitive-processor cycle time over the 20- to 70-year age range, then the model could not have fit Gregoire and Van der Linden's (1997) reported memory spans closely.
} 
information-processing requirements of memory-span tasks to be specified thoroughly and precisely.

\section{QUESTIONS AND ANSWERS ABOUT COGNITIVE AGEING}

On the basis of our preceding discourse, we can now use EPIC's premises to accept Newell's (1973) challenge and tentatively answer 20 fundamental questions about cognitive ageing.

\section{Question 1: What are the sources of age-related slowing?}

Answer: According to EPIC, age-related slowing stems from changes in various "hardware" and "software" components of the informationprocessing system. Like some others (e.g., Bashore, Osman, \& Heffley, 1989; Fisher \& Glaser, 1996; Fisk, Fisher, \& Rogers, 1992; Madden, 1992; Sliwinski, 1997), we endorse specialised-slowing hypotheses about selective effects of ageing on distinct processing stages. Yet in one key respect, our theoretical position abides by the generalised-slowing hypothesis (cf. Birren, Woods, \& Williams, 1980; Cerella, 1985; Salthouse, 1978b, 1985). For every task, an age-related increase of the mean cycle time in EPIC's cognitive processor presumably contributes to longer RTs.

\section{Question 2: Why does perceptual speed account for} so much age-related variance in performance?

Answer: Perceptual speed has been measured with tasks like digit-symbol substitution and alphanumeric-string comparison (Salthouse, 1996). However, when analysed in terms of EPIC, these tasks are not simple; they presumably evoke a whole microcosm of complex cognition. Performing them requires assorted hardware (visual, ocular, manual, cognitive processors) and software (executive control, search, judgement, response selection, rechecking). The speed of this performance may embody effects of ageing on all of these components, so it can account for much age-related variance in performance of other tasks to which some of these same components contribute. Our research has revealed that virtually no task is truly simple. This pervasive complexity must be understood in detail to characterise cognitive ageing.

\section{Question 3: How much does perceptual-motor} hardware contribute to age-related slowing?

Answer: Time increments contributed by "peripheral" perceptual-motor hardware to lengthened RTs sometimes seem to embody relatively small 
$(<20 \%)$ ageing effects (e.g., Bashore, 1994; Cerella, 1985). Nevertheless, our EPIC models reveal that such increments may increase by much larger percentages with age. In accounting for Gregoire and Van der Linden's (1997) memory spans, estimated mean durations of speech production by older adults were over $40 \%$ longer than those of the young (Table 3). In accounting for Glass et al.'s (2000) dual-task RTs, estimated mean durations of auditory stimulus identification by older adults were over $100 \%$ longer (Table 2). Thus, age-related changes of perceptual-motor hardware should be taken seriously even when older adults have to perform tasks that are mainly "cognitive" (cf. Baltes \& Lindenberger, 1997; Welford, 1977).

\section{Question 4: How much does central cognitive hardware contribute to age-related slowing?}

Answer: Our modelling shows that ageing from 20 to 70 years increases the mean cycle time of the cognitive processor by about $13 \%$, which may contribute more or less to age-related differences between RTs, depending on how many processing cycles are taken to complete a task (cf. Cerella, 1985; Cerella, Poon, \& Williams, 1980). Other hardware changes associated with ageing may also affect these RT differences indirectly. For example, because of shorter WM decay times, elderly adults may need more elaborate procedures to perform some tasks correctly (Mayr \& Kliegl, 1993; Salthouse, 1996). This requirement, along with increased cycle times, can lengthen RTs significantly.

\section{Question 5: How much does central cognitive software contribute to age-related slowing?}

Answer: Old/young time ratios are sometimes between 1.1 and 1.2 (Cerella, 1985). When this occurs, it may stem entirely from the increase of about $13 \%$ in the mean cognitive-processor cycle time, implying that less efficient cognitive software has not contributed to older adults' slowing. Nevertheless, old/young time ratios are sometimes much greater than 1.2 (Cerella, 1985; Mayr \& Kliegl, 1993). Then one may infer that older adults have used cognitive software whose execution takes more processor cycles than that of the young. The proportional amount by which an old/young time ratio exceeds 1.13 quantifies how much a software difference has contributed to age-related slowing in terms of proportionally more cycles being taken. For example, a 2.26 ratio relative to 1.13 would imply that older adults have taken twice as many cycles as young adults. Such increases are manifested in both the unlocking durations of the executive process and the response-selection times of the hard Task 2 process for our AEC model of dual-task performance by older adults (Table 2 ). 


\section{Question 6: Why are some Brinley plots linear?}

Answer: Brinley (1965) plots are graphs that depict mean RTs of older adults paired with mean RTs of young adults for each of several tasks (e.g., Figure 8). According to EPIC, these plots will be linear when increased task complexity leads older adults to use either the same number of additional cognitive-processor cycles as the young do, or proportionally more cycles. This prediction, which is supported by some data of Mayr and Kliegl (1993), agrees with the classic complexity hypothesis (Birren, 1965) and results from some meta-analyses of agerelated slowing (e.g., Cerella, 1985).

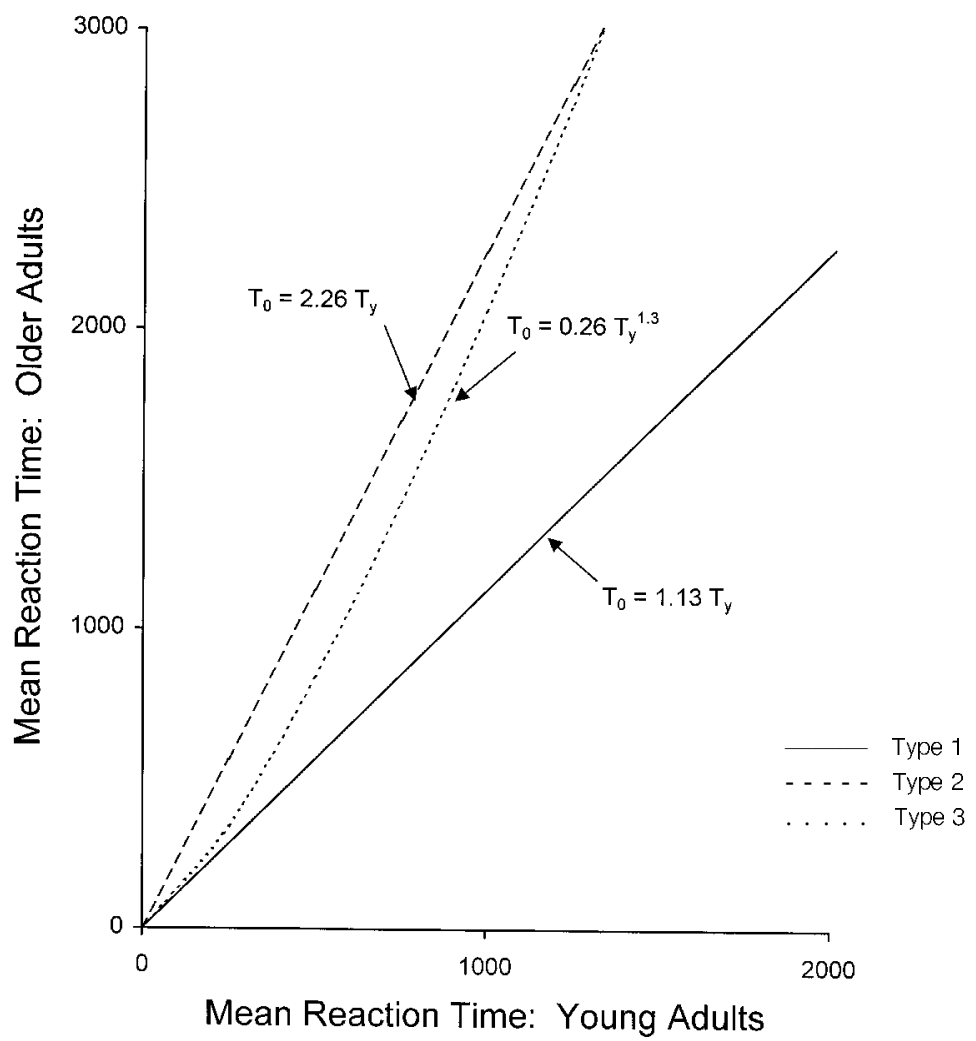

Figure 8. Idealised Brinley plots of alternative quantitative relationships between mean reaction times (RTs) of young and older adults for tasks whose complexity varies. Type 1: Linear old/young RT function with shallow 1.13 slope. Type 2: Linear old/young RT function with steep 2.26 slope. Type 3: Positively accelerated old/young RT function. 


\section{Question 7: Why are slopes of some linear Brinley plots very shallow?}

Answer: Some linear Brinley plots (e.g., Figure 8, solid line) have very shallow slopes because they include a proportional age-related increase of $13 \%$ in the mean cognitive-processor cycle time, with no accompanying differences between young and older adults' cognitive software. Such shallowness is most likely when basic RT tasks are involved. For them, both age groups may use identical or very similar rule sets whose execution takes the same numbers of cycles.

\section{Question 8: Why are slopes of some linear Brinley plots much steeper?}

Answer: Some linear Brinley plots have steeper slopes (e.g., Figure 8, dashed line) because as task complexity increases, older adults may use rule sets whose execution takes proportionally more cognitive-processor cycles than the young. This could stem from effects of ageing on skill acquisition. For example, within EPIC, skill acquisition involves at least three phases (Kieras et al., 2000). First, declarative knowledge about how to perform a given task is acquired. Second, production rules are compiled from this knowledge to create executable task procedures. Third, these rules are refined through practice to enhance their efficiency. For some complex tasks, perhaps older adults initially compile inefficient rule sets whose execution takes proportionally more processor cycles than those of the young (cf. Mayr \& Kliegl, 1993). This inefficiency, combined with certain learning functions for rule refinement, would yield linear Brinley plots whose slopes exceed 1.13. ${ }^{17}$

${ }^{17}$ To be precise, suppose that for each of $J$ tasks whose complexity varies, $n_{\mathrm{oj} 1}=g\left(n_{\mathrm{yj} 1}\right)$, where $n_{\mathrm{yj} 1}$ is the number of processor cycles taken by young adults' production rules on the first trial of practice for the $\mathrm{j}^{\text {th }}$ task $(1 \leqslant j \leqslant J), n_{\mathrm{oj} 1}$ is the number of cycles taken by older adults' rules on the first trial, and $g$ is a function that relates $n_{\mathrm{oj} 1}$ to $n_{\mathrm{yj} 1}$. Also suppose that $n_{\mathrm{yjm}}=f_{\mathrm{y}}(m)$ and $n_{\mathrm{ojm}}=f_{\mathrm{o}}(m)$, where $n_{\mathrm{yjm}}$ is the number of cycles taken by the young adults' rules on the $\mathrm{m}^{\text {th }}$ trial $(m \geqslant 1), n_{\mathrm{ojm}}$ is the number of cycles taken by the older adults' rules on the $\mathrm{m}^{\text {th }}$ trial, $f_{\mathrm{y}}$ is a learning function for young adults, $f_{\mathrm{o}}$ is a learning function for older adults, and $f_{\mathrm{o}}(m)=g\left[f_{\mathrm{y}}(m)\right]$. Then the Brinley plot of mean RTs for these tasks would have the same type of form as $g$. For example, if $g\left(n_{\mathrm{yj} 1}\right)=k n_{\mathrm{yj} 1}$, so that $n_{\mathrm{oj} 1}$ is larger than $n_{\mathrm{yj} 1}(1 \leqslant$ $j \leqslant J)$ by a proportional constant $(k>1)$, then the Brinley plot would be linear with a slope of $1.13 \mathrm{k}$, where 1.13 is the proportional amount by which the mean cognitive-processor cycle time of older adults exceeds the young adults' mean cycle time. Also, if the young adults' learning function, $f_{\mathrm{y}}(m)$, conforms to the power law of practice (Anderson, 1983; Newell, 1990) such that $n_{\mathrm{yjm}}=a+b m^{-r}$, where $a \geqslant 0, b>0$, and $r>0$, then the older adults' learning function, $f_{\mathrm{o}}(m)$, would conform to the power law of practice with $f_{\mathrm{o}}(m)=k\left(a+b m^{-}\right.$ $\left.{ }^{r}\right)$. Alternatively, if $\mathrm{g}$ makes $n_{\mathrm{oj} 1}$ be disproportionally larger than $n_{\mathrm{yj} 1}(1 \leqslant j \leqslant J)$, this different relationship — combined with the other previous assumptions - would yield a positively accelerated Brinley plot, and the older adults' learning function would not necessarily conform to the power law of practice when that of the young adults does. 


\section{Question 9: Why are some Brinley plots nonlinear?}

Answer: Nonlinear Brinley plots (e.g., Figure 8, dotted curve) can occur for two reasons. First, they may come from conjoining segments of linear old/young RT functions whose slopes subtly differ (Mayr \& Kliegl, 1993). Second, for some complex tasks, older adults may compile inefficient rule sets whose execution takes disproportionately more cycles than those of the young. This inefficiency, combined with certain learning functions (see footnote 17), would yield positively accelerated Brinley plots (e.g., Hale, Myerson, \& Wagstaff, 1987). Our claim here differs from Cerella's (1990) overhead and Myerson, Hale, Wagstaff, Poon, and Smith's (1990) information-loss hypotheses, which assume a correspondence axiom that young and older adults use the same sequence of algorithmic steps for performing a given task.

\section{Question 10: Is the correspondence axiom correct?}

Answer: Perhaps sometimes, but not often. When a set of tasks yields a linear Brinley plot whose slope is about 1.13 (e.g., Figure 8, solid line), it is plausible to conclude that young and older adults have used the same algorithmic steps, consistent with the correspondence axiom. However, when Brinley plots have steeper linear or positively accelerated RT functions, another plausible conclusion is that the two age groups have compiled rule sets whose execution takes different numbers of algorithmic steps, contrary to this axiom. In fact, there are probably many circumstances where the correspondence axiom does not hold when complex tasks have to be performed.

\section{Question 11: Are there qualitatively different types of task complexity?}

Answer: Perhaps, but more research is needed to understand what the complexities are. For example, Mayr \& Kliegl (1993, p. 1298) distinguished between sequential and coordinative complexity. Sequential complexity involves "a variation in the number of independent processing steps that does not increase the amount of information exchange between single steps", whereas coordinative complexity involves a variation in "the amount of processing required to regulate and monitor the flow of information between interrelated processing steps". Supporting this distinction, 
Mayr and Kliegl obtained linear Brinley plots with steeper slopes for manipulation of coordinative complexity. However, others (e.g., Brinley, 1965; McDowd \& Craik, 1988) have not obtained such results. Nor does our research show that moderately older adults $(60 \leqslant$ age $\leqslant 70$ years $)$ are always impaired at coordinative information processing. Instead ageing effects on coordinative information processing may stem from malleable differences between strategies adopted to manage performance when both WM and perceptual-motor loads are heavy. Taking these strategy differences fully into account will be crucial for aptly distinguishing alternative types of task complexity.

\section{Question 12: Why do some measures of WM capacity decrease very little with age?}

Answer: Modelling with EPIC has yielded three results that, in combination, explain why older adults perform almost as well as the young on basic WM tasks. First, from 20 to 70 years of age, the mean cognitiveprocessor cycle time increases by only $13 \%$. Second, decay times of phonological codes in verbal WM remain essentially constant until at least 70 years of age. Third, over a broad age range, concurrent threads of information processing can be executed for multiple tasks. These abilities, when exploited by efficient task procedures, can yield rather stable measures of WM capacity across much of the life span. For example, this accounts for the well-preserved forward, backward, and $n$-back memory spans reported in studies of ageing and verbal WM (e.g., Dobbs \& Rule, 1989; Gregoire \& Van der Linden, 1997).

\section{Question 13: Why do some measures of WM capacity decrease much more than others with age?}

Answer: Larger age-related decreases in measures of WM capacity have been obtained with reading-span, calculation-span, and other relatively complex tasks (e.g., Foos, 1989; Gick et al., 1988; Wingfield et al., 1988). One possible explanation for this is that studies with such tasks have included many very old adults, whose WM components are more impaired than those in moderately old adults. A second important possibility is that as adults grow older, they tend to adopt cautious strategies for performing complex WM tasks, thereby neglecting to exploit their available cognitive capacities. However, from our research, it appears that, before 70 years of age, older adults retain great potential for coordinative and executive information processing. If so, then training that 
improves their strategies could enable them to manifest high capacity even for complex WM tasks.

\section{Question 14: Is inhibitory control impaired with age?}

Answer: We have obtained no compelling evidence that inhibitory control is impaired with age. EPIC models of memory span suggest that older adults are not especially distracted by discarded information in WM. Similarly, in our PRP experiments (Glass et al., 2000), older adults were not more distracted than the young by secondary-task stimuli during primary-task performance. Their mean primary-task RTs were essentially independent of SOA, and out-of-order secondary-task responses were extremely rare, yet older adults identified stimuli and selected responses concurrently for the two tasks. These results suggest that inhibitory control has been preserved. This is consistent with a variety of data on ageing and Stroop colour-word interference (Salthouse \& Meinz, 1995; Verhaeghen \& De Meersman, 1998), inhibition of return (Faust \& Balota, 1997; Hartley \& Kieley, 1995), visual marking (Kramer \& Atchley, 2000), and negative priming (Sullivan \& Faust, 1993). ${ }^{18}$

Nevertheless, some researchers (e.g., Dempster, 1992; Hasher \& Zacks, 1988; Rabbitt, 1965) have hypothesised that ageing impairs inhibitory control. Consistent with this, older adults are disproportionately slower when reading text that contains irrelevant information at unpredictable locations (Connelly, Hasher, \& Zacks, 1991), and older adults' negative priming is sometimes less than that of the young (Hasher, Stoltzfus, Zacks, \& Rypma, 1991; Kane, Hasher, Stoltzfus, Zacks, \& Connelly, 1994; McDowd \& Oseas-Kreger, 1991; Stolzfus, Hasher, Zacks, Ulivi, \& Goldstein, 1993; Tipper, 1991). However, these results may stem at least partly from ageing effects on peripheral perceptual-motor mechanisms rather than central inhibition (Murphy, McDowd, \& Wilcox, 1999; Scialfa, Hamaluk, Skaloud, \& Pratt, 1999). Also, inhibitory control may seem impaired if older adults adopt visual inspection strategies that expose them to more irrelevant information but have other compensatory benefits. ${ }^{19}$

\footnotetext{
${ }^{18}$ For a thorough review of relevant studies like these, see Kramer, Humphrey, Larish, Logan, and Strayer (1994).

${ }^{19}$ For example, inspection strategies with more closely spaced and redundant visual fixation points might make it harder to ignore irrelevant information but help compensate for age-related random noise in the perceptual and motor systems (cf. Scialfa et al., 1999; Welford, 1977).
} 


\section{Question 15: Have older adults lost their ability to time-share during dual-task performance?}

Answer: Standard wisdom about cognitive ageing proclaims that older adults lose their ability to time-share during dual-task performance (McDowd, Vercruyssen, \& Birren, 1991). "One of the clearest results in the experimental psychology of aging is that older subjects are more penalized when they must divide their attention" (Craik, 1977, p. 391). Lost time-sharing ability seems apparent from many studies in which disproportionate dual-task costs occurred with age (e.g., Allen et al., 1998; Crossley \& Hiscock, 1992; Guttentag \& Madden, 1987; Hawkins, Kramer, \& Capaldi, 1992; Korteling, 1991; Lorsbach \& Simpson, 1988; Ponds, Brouwer, \& van Volfelaar, 1988). However, close perusal reveals that these studies perhaps should be discounted somewhat because of how their data were collected and analysed. Our work with the PRP procedure suggests that older adults still time-share efficiently when encouraged to do so.

\section{Question 16: Do older adults suffer from goal neglect?}

Answer: Because the brain's frontal lobes deteriorate with age (Raz, 2000; West, 1996), older adults may suffer goal neglect, a symptom of "dysexecutive syndrome" (Baddeley, 1986; Duncan, 1986, 1995; West \& Baylis, 1998). Goal neglect involves inadequate readiness or "set" for tasks. This could occur if items like "GOAL: DO TASK A" and "GOAL: DO TASK B" are not inserted and maintained in WM. Nevertheless, we have evidence that adults may be spared from goal neglect before 70 years of age. If goal neglect affected them, then our EPIC models - which assume intact usage of goals - would have failed to fit older adults' dual-task RTs and memory spans. Beyond age 70, however, other results from our models suggest that task goals in WM may become less resilient.

\section{Question 17: How are age-related slowing and skill acquisition associated?}

Answer: Like some researchers (e.g., Fisk \& Rogers, 1991; Kramer, Larish, Weber, \& Bardell, 1999; Strayer \& Kramer, 1994), we believe skill acquisition and age-related slowing are closely associated. Many tasks used to measure RTs and time-sharing costs are initially novel to participants. Strategies that older adults adopt to cope with this novelty, and the mechanisms that they use to modify their strategies, determine response speed and accuracy. Taking these matters seriously enables EPIC to account for steeply sloped linear and positively accelerated 
Brinley plots. Other researchers have provided such accounts for both single-task (e.g., Fisk \& Rogers, 1991; Strayer \& Kramer, 1994) and dualtask (e.g., Kramer et al., 1999) performance. In particular, the extent to which older adults time-share well between dual-tasks is affected by the type of training they receive. This is what we expect based on EPIC's emphasis of adaptive executive control and flexible task management.

\section{Question 18: What strategies can and should older adults adopt to cope with cognitive ageing?}

Answer: Much evidence shows that older adults tend to adopt conservative strategies for performing speeded tasks (e.g., Baron \& Matilla, 1989; Botwinick, 1966; Okun \& Di Vesta, 1976; Rabbitt, 1979; Salthouse, 1978a; Salthouse \& Somberg, 1982; Strayer, Wickens, \& Braune, 1987). Three factors could underlie this tendency. First, mechanisms for compiling procedural knowledge may become less optimal with age and generate initial inefficient sets of production rules. Second, older adults' cautiousness may be warranted because of their reduced processing capacities. Third, older adults may prefer conservative strategies because they do not fully appreciate their preserved capacities. From our EPIC models, it appears that the first and second factors perhaps prevail after age 70 . Before then, the third factor may be more important because, until age 70, relatively little is lost in terms of cognitive-processor speed, WM trace durability, and some other hardware parameters. Thus, adults under 70 should be encouraged to exploit the capacities that they still have.

\section{Question 19: Is cognitive ageing a gradual uniform process?}

Answer: Cognitive ageing is not gradual and uniform in all respects. Some "hardware" parameters like the mean cognitive-processor cycle time change modestly over the life span. Other parameters, such as WM decay times, remain almost constant until 70 years of age, but change more rapidly thereafter. Meanwhile, cognitive software for performing tasks may vary greatly, depending on task priorities, personal predilections, training, and other contextual factors. This pattern implies that although meritorious, hypotheses about specific age-related effects may not hold for all adult subgroups. Special care is needed to interpret results from each subgroup. Characterising their performance requires models that accommodate complex interactions between the more or less functional and ever-changing components of the adult informationprocessing system. 


\section{Question 20: Where should future research on cognitive ageing go from here?}

Answer: Future research on cognitive ageing may take several promising paths. Steps toward unified computational theories of cognitive ageing should continue. More work is needed to identify ageing effects on hardware and software components of information processing. Changes in perceptual-motor hardware mechanisms and their interactions with central cognitive software must be better understood. Closer attention must be directed to the different types of executive-control strategies and task procedures adopted by young and older adults. Also, it will be important to credit contributions of skill acquisition more fully in assessing the ultimate performance levels that older adults can achieve. From so doing, far more than 20 questions about cognitive ageing will be answered during the 21 st century.

Manuscript received September 2000

\section{REFERENCES}

Allen, P.A., Smith, A.F., Vires-Collins, H., \& Sperry, S. (1998). The psychological refractory period: Evidence for age differences in attentional time-sharing. Psychology and Aging, $13,218-229$.

Allport, D.A. (1987). Selection-for-action: Some behavioral and neurophysiological considerations of attention and action. In H. Heuer \& A.F. Sanders (Eds.), Perspectives on perception and action (pp. 395-419). Hillsdale, NJ: Lawrence Erlbaum Associates Inc.

Anderson, J.R. (1983). The architecture of cognition. Cambridge, MA: Harvard University Press.

Babcock, R.L., \& Salthouse, T.A. (1990). Effects of increased processing demands on age differences in working memory. Psychology and Aging, 5, 421-428.

Baddeley, A.D. (1986). Working memory. New York: Oxford University Press.

Baddeley, A.D., Logie, R., Bressi, S., Della Sala, S., \& Spinnler, H. (1986). Dementia and working memory. Quarterly Journal of Experimental Psychology, 38A, 603-618.

Baddeley, A.D., Thomson, N., \& Buchanan, M. (1975). Word length and the structure of short-term memory. Journal of Verbal Learning and Verbal Behavior, 14, 575-589.

Baltes, P.B., \& Lindenberger, U. (1997). Emergence of a powerful connection between sensory and cognitive functions across the adult life span: A new window to the study of cognitive aging? Psychology and Aging, 12, 12-21.

Baron, A., \& Matilla, W.R. (1989). Response slowing of older adults: Effects of time-limit contingencies on single- and dual-task performance. Psychology and Aging, 4, 66-72.

Bashore, T.R. (1994). Some thoughts on neurocognitive slowing. Acta Psychologica, 86, 295-325.

Bashore, T.R., Osman, A.M., \& Heffley, E.F. (1989). Mental slowing in elderly adults: A cognitive psychophysiological analysis. Psychology and Aging, 4, 235-244.

Birren, J.E. (1965). Age changes in speed of behavior: Its central nature and physiological 
correlates. In A.T. Welford \& J.E. Birren (Eds.), Behavior, aging, and the nervous system (pp. 191-216). Springfield, IL: Thomas.

Birren, J.E., Woods, A.M., \& Williams, M.V. (1980). Behavioral slowing with age: Causes, organization, and consequences. In L.W. Poon (Ed.), Aging in the 1980s (pp. 293-308). Washington, DC: American Psychological Association.

Botwinick, J. (1996). Cautiousness in old age. Journal of Gerontology, 21, 347-353.

Botwinick, J., \& Storandt, M. (1974). Memory, related functions and age. Springfield, IL: Charles C. Thomas.

Brinley, J.F. (1965). Cognitive sets, speed and accuracy of performance in the elderly. In A.T. Welford \& J.E. Birren (Eds.), Behavior, aging, and the nervous system (pp. 114149). Springfield, IL: Thomas.

Bromley, D.B. (1958). Some effects of age on short-term learning and remembering. Journal of Gerontology, 12, 398-406.

Burke, D.M., \& Yee, P.L. (1984). Semantic priming during sentence processing by young and older adults. Developmental Psychology, 20, 903-910.

Byrne, M.D. (1998). Taking a computational approach to aging: The SPAN theory of working memory. Psychology and Aging, 13, 309-322.

Callaway, E., \& Yeager, C.L. (1960). Relationship between reaction time and electroencephalographic alpha base. Science, 132, 1765-1766.

Card, S.K., Moran, T.P., \& Newell, A. (1983). The psychology of human-computer interaction. Hillsdale, NJ: Lawrence Erlbaum Associates Inc.

Cerella, J. (1985). Information processing rates in the elderly. Psychological Bulletin, 98, 6783.

Cerella, J. (1990). Aging and information-processing rate. In J.E. Birren \& K.W. Schaie (Eds.), Handbook of the psychology of aging (3rd ed., pp. 201-221). New York: Academic Press.

Cerella, J., Poon, L.W., \& Williams, D.M. (1980). Age and the complexity hypothesis. In L.W. Poon (Ed.), Aging in the 1980s (pp. 332-340). Washington, DC: American Psychological Association.

Charness, N. (1981). Visual short-term memory and aging in chess players. Journal of Gerontology, 36, 615-619.

Clark, L.E., \& Knowles, J.B. (1973). Age differences in dichotic listening performance. Journal of Gerontology, 28, 173-178.

Connelly, S.L., Hasher, L., \& Zacks, R.T. (1991). Age and reading: The impact of distraction. Psychology and Aging, 6, 533-541.

Craik, F.I.M. (1968). Two components in free recall. Journal of Verbal Learning and Verbal Behavior, 7, 996-1004.

Craik, F.I.M. (1977). Age differences in human memory. In J.E. Birren \& K.W. Schaie (Eds.), Handbook of the psychology of aging (pp. 384-420). New York: Van Nostrand Reinhold.

Craik, F.I.M., \& Byrd, M. (1982). Aging and cognitive deficits: The role of attentional resources. In F.I.M. Craik \& A.S. Trehub (Eds.), Aging and cognitive processes (pp. 191211). New York: Plenum.

Craik, F.I.M., \& Jennings, J.M. (1992). Human memory. In F.I.M. Craik \& T.A. Salthouse (Eds.), The handbook of aging and cognition (pp. 51-110). Hillsdale, NJ: Lawrence Erlbaum Associates Inc.

Craik, F.I.M., \& Salthouse, T.A. (Eds.). (2000). The handbook of aging and cognition (2nd ed.). Mahwah, NJ: Lawrence Erlbaum Associates Inc.

Crossley, M., \& Hiscock, M. (1992). Age-related differences in concurrent-task performance of normal adults: Evidence for a decline in processing resources. Psychology and Aging, 7, 499-506. 
Dempster, F.N. (1992). The rise and fall of the inhibitory mechanism: Toward a unified theory of cognitive development and aging. Developmental Review, 12, 45-75.

D’Esposito, M., \& Postle, B.R. (1999). The dependence of span and delayed response performance on prefrontal cortex. Neuropsychologia, 37, 1303-1315.

Dobbs, A.R., \& Rule, B.G. (1989). Adult age differences in working memory. Psychology and Aging, 4, 500-503.

Drewnowski, A. (1980). Attributes and priorities in short-term recall: A new model of memory span. Journal of Experimental Psychology: General, 109, 208-250.

Duncan, J. (1986). Disorganization of behaviour after frontal-lobe damage. Cognitive Neuropsychology, 3, 271-290.

Duncan, J. (1995). Attention, intelligence, and the frontal lobes. In M.S. Gazzaniga (Ed.), The cognitive neurosciences (pp. 721-733). Cambridge, MA: MIT Press.

Faust, M.E., \& Balota, D.A. (1997). Inhibition of return and visuospatial attention in healthy older adults and individuals with dementia of the Alzheimer types. Neuropsychology, 11, 13-29.

Ferris, S.H., Crook, T., Clark, E., McCarthy, M., \& Rae, D. (1980). Facial recognition memory deficits in normal aging and senile dementia. Journal of Gerontology, 35, 707-714.

Fisher, D.L., \& Glaser, R.A. (1996). Molar and latent models of cognitive slowing: Implications for aging, dementia, depression, development, and intelligence. Psychonomic Bulletin and Review, 3, 458-480.

Fisk, A.D., Fisher, D.L., \& Rogers, W. (1992). General slowing alone cannot explain agerelated search effects: Reply to Cerella (1991). Journal of Experimental Psychology: General, 121, 73-78.

Fisk, A.D., \& Rogers, W. (1991). Toward an understanding of age-related memory and visual search effects. Journal of Experimental Psychology: General, 120, 131-149.

Foos, P.W. (1989). Adult age differences in working memory. Psychology and Aging, 4, 269275.

Gick, M.L., Craik, F.I.M., \& Morris, R.G. (1988). Task complexity and age differences in working memory. Memory \& Cognition, 16, 353-361.

Glass, J.M. (2000, April). Visual function and cognitive aging: Differential role of contrast sensitivity in verbal versus spatial tasks. Paper presented at the Cognitive Aging Conference, Atlanta, GA.

Glass, J.M., Schumacher, E.H., Lauber, E.J., Zurbriggen, E.L., Gmeindl, L., Kieras, D.E., \& Meyer, D.E. (2000). Aging and the psychological refractory period: Task-coordination strategies in young and old adults. Psychology and Aging, 15, 571-595.

Gregoire, J., \& Van der Linden, M. (1997). Effects of age on forward and backward digit spans. Aging, Neuropsychology, and Cognition, 4, 140-149.

Guttentag, R.E., \& Madden, D.J. (1987). Adult age differences in the attentional capacity demands of letter matching. Experimental Aging Research, 13, 93-98.

Hale, S., Myerson, J., \& Wagstaff, D. (1987). General slowing of nonverbal information processing: Evidence for a power law. Journal of Gerontology, 42, 131-136.

Hartley, A.A., \& Kieley, J.M. (1995). Adult age differences in the inhibition of return of visual attention. Psychology and Aging, 10, 670-683.

Hartley, A.A., \& Little, D.M. (1999). Age-related differences and similarities in dual-task interference. Journal of Experimental Psychology: General, 128, 416-449.

Hasher, L., Stoltzfus, E.R., Zacks, R.T., \& Rypma, B. (1991). Age and inhibition. Journal of Experimental Psychology: Learning, Memory, and Cognition, 17, 163-169.

Hasher, L., \& Zacks, R.T. (1988). Working memory, comprehension, and aging: A review and a new view. In G.H. Bower (Ed.), The psychology of learning and motivation (Vol. 22, pp. 193-225). San Diego, CA: Academic Press.

Hastings, N.A.J., \& Peacock, J.B. (1975). Statistical distributions. London: Butterworth. 
Hawkins, H.L., Kramer, A.F., \& Capaldi, D. (1992). Aging, exercise, and attention. Psychology and Aging, 7, 643-653.

Hooper, F.H., Hooper, J.O., \& Colbert, K.C. (1984). Personality and memory correlates of intellectual functioning: Young adulthood to old age. Basel, Switzerland: Karger.

Kail, R., \& Salthouse, T.A. (1994). Processing speed as mental capacity. Acta Psychologica, 86, 199-226.

Kane, M.J., Hasher, L., Stoltzfus, E.R., Zacks, R.T., \& Connelly, S.L. (1994). Inhibitory attentional mechanisms and aging. Psychology and Aging, 9, 103-112.

Keele, S.W. (1973). Attention and human performance. Pacific Palisades, CA: Goodyear.

Kieras, D.E., \& Meyer, D.E. (1997). An overview of the EPIC architecture for cognition and performance with application to human-computer interaction. Human-Computer Interaction. 12, 391-438.

Kieras, D.E., \& Meyer, D.E. (2000). The role of cognitive task analysis in the application of predictive models of human performance. In J.M. Schraagen, S.F. Chipman, \& V.L. Shalin (Eds.), Cognitive task analysis (pp. 237-260). Mahwah, NJ: Lawrence Erlbaum Associates Inc.

Kieras, D.E., Meyer, D.E., Ballas, J.A., \& Lauber, E.J. (2000). Modern computational perspectives on executive mental control: Where to from here? In S. Monsell \& J. Driver (Eds.), Attention and performance XVIII: Control of cognitive processes (pp. 681-712). Cambridge, MA: MIT Press.

Kieras, D.E., Meyer, D.E., Mueller, S., \& Seymour, T. (1999) Insights into working memory from the perspective of the EPIC architecture for modeling skilled perceptual-motor and cognitive human performance. In A. Miyake \& P. Shah (Eds.), Models of working memory: Mechanisms of active maintenance and executive control (pp. 183-223). New York: Cambridge University Press.

Korteling, J. (1991). Effects of skill integration and perceptual competition on age-related differences in dual-task performance. Human Factors, 33, 35-44.

Kramer, A.F., \& Atchley, P. (2000). Age-related effects in the marking of old objects in visual search. Psychology and Aging, 15, 286-296.

Kramer, A.F., Humphrey, D.G., Larish, J.F., Logan, G.D., \& Strayer, D.L. (1994). Aging and inhibition: Beyond a unitary view of inhibitory processing in attention. Psychology and Aging, 9, 491-512.

Kramer, A.F., Larish, J.L., Weber, T.A., \& Bardell, L. (1999). Training for executive control: Task coordination strategies and aging. In D. Gopher \& A. Koriat (Eds.), Attention and performance XVII (pp. 617-652). Cambridge, MA: MIT Press.

Kristofferson, A.B. (1967). Attention and psychophysical time. In A.F. Sanders (Ed.), Attention and performance (pp. 93-100). Amsterdam: North-Holland Publishing Co.

Landauer, T.K. (1962). The rate of implicit speech. Perceptual and Motor Skills, 15, 646.

Light, L.L., \& Anderson, P.A. (1985). Working-memory capacity, age, and memory for discourse. Journal of Gerontology, 40, 737-747.

Longoni, A.M., Richardson, A.T.E., \& Aiello, A. (1993). Articulatory rehearsal and phonological storage in working memory. Memory \& Cognition, 21, 11-22.

Lorsbach, T., \& Simpson, G. (1988). Dual-task performance as a function of adult age and task complexity. Psychology and Aging, 243, 210-212.

Madden, D.J. (1992). Four to ten milliseconds per year: Age-related slowing of visual word identification. Journal of Gerontology: Psychological Sciences, 47, P59-P68.

Marsh, G.R., \& Thompson, L.W. (1977). Psychophysiology of aging. In J.E. Birren \& K.W. Schaie (Eds.), Handbook of the psychology of aging (pp. 219-248). New York: Van Nostrand Reinhold.

Maylor, E.A., Vousden, J.I., \& Brown, G.D.A. (1999). Adult age differences in short-term memory for serial order: Data and a model. Psychology and Aging, 14, 572-594. 
Mayr, U., \& Kliegl, R. (1993). Sequential and coordinative complexity: Age-based processing limitations in figural transformations. Journal of Experimental Psychology: Learning, Memory, and Cognition, 19, 1297-1320.

Mayr, U., \& Kliegl, R. (2000). Complex semantic processing in old age: Does it stay or does it go? Psychology and Aging, 15, 29-43.

McDowd, J.M., \& Craik, F.I.M. (1988). Effects of aging and task difficulty on divided attention performance. Journal of Experimental Psychology: Human Perception and Performance, 14, 267-280.

McDowd, J.M., \& Oseas-Kreger, D.M. (1991). Aging, inhibitory processes, and negative priming. Journal of Gerontology: Psychological Sciences, 46, P340-P345.

McDowd, J.M., Vercruyssen, M., \& Birren, J.E. (1991). Aging, divided attention, and dualtask performance. In D.L. Damos (Ed.), Multiple task performance (pp. 387-414). Bristol, PA: Taylor \& Francis.

Meyer, D.E., \& Kieras, D.E. (1997a). A computational theory of executive cognitive processes and multiple-task performance: Part 1. Basic mechanisms. Psychological Review, $104,3-65$.

Meyer, D.E., \& Kieras, D.E. (1997b). A computational theory of executive cognitive processes and multiple-task performance: Part 2. Accounts of psychological refractory-period phenomena. Psychological Review, 104, 749-791.

Meyer, D.E., \& Kieras, D.E. (1999). Précis to a practical unified theory of cognition and action: Some lessons from computational modeling of human multiple-task performance. In D. Gopher \& A. Koriat (Eds.), Attention and performance XVII (pp. 17-88). Cambridge, MA: MIT Press.

Meyer, D.E., Mueller, S.T., Seymour, T.L., \& Kieras, D.E. (2000, April). Brain loci of temporal coding and serial-order control for verbal working memory revealed by computational modeling and focal lesion analysis of memory-span performance. Poster presented at the meeting of the Cognitive Neuroscience Society, San Francisco, CA.

Mueller, S.T., Seymour, T.L., Glass, J.M., Kieras, D.E., \& Meyer, D.E. (2000, April). Components of cognitive aging in verbal working memory revealed by computational modeling with the executive-process interactive control (EPIC) architecture. Poster presented at the Cognitive Aging Conference, Atlanta, GA.

Murphy, D.R., McDowd, J.M., \& Wilcox, K.A. (1999). Inhibition and aging: Similarities between younger and older adults revealed by the processing of unattended auditory information. Psychology and Aging, 14, 44-59.

Myerson, J., Hale, S., Wagstaff, D., Poon, L.W., \& Smith, G.A. (1990). The informationloss model: A mathematical theory of age-related cognitive slowing. Psychological Review, 97, 475-487.

Newell, A. (1973). You can't play 20 questions with nature and win. In W.G. Chase (Ed.), Visual information processing (pp. 283-308). New York: Academic Press.

Newell, A. (1990). Unified theories of cognition. Cambridge, MA: Harvard University Press.

Obrist, W.D., \& Busse, E.W. (1965). The electroencephalogram in old age. In W.W. Wilson (Ed.), Applications of electroencephalography in psychiatry: A symposium (pp. 185-205). Durham, NC: Duke University Press.

Okun, M.A., \& Di Vesta, F.J. (1976). Cautiousness in adulthood as a function of age and instructions. Journal of Gerontology, 31, 571-576.

Orsini, A.L., Chiacchio, L., Cinque, M., Cocchiaro, C., Schiappa, O., \& Grossi, D. (1986). Effects of age, education and sex on two tests of immediate memory: A study of normal subjects from 20 to 99 years of age. Perceptual and Motor Skills, 63, 727-732.

Park, D.C., Smith, A.D., Lautenschlager, G., Earles, J., Frieske, D., Zwahr, M., \& Gaines, C.L. (1996). Mediators of long-term memory performance across the life span. Psychology and Aging, 11, 621-637. 
Pashler, H. (1994). Dual-task interference in simple tasks: Data and theory. Psychological Bulletin, 116, 220-244.

Ponds, R.W., Brouwer, W.H., \& van Volfelaar, P.C. (1988). Age differences in divided attention in a simulated driving task. Journal of Gerontology, 43, P151-P156.

Puckett, J.M., \& Stockburger, D.W. (1988). Absence of age-related proneness to short-term retroactive interference in the absence of rehearsal. Psychology and Aging, 3, 342-347.

Rabbitt, P.M.A. (1965). An age-decrement in the ability to ignore irrelevant information. Journal of Gerontology, 20, 233-238.

Rabbitt, P.M.A. (1979). How old and young subjects monitor and control responses for accuracy and speed. British Journal of Psychology, 70, 305-311.

Raymond, B.J. (1971). Free recall among the aged. Psychological Reports, 29, 1179-1182.

Raz, N. (2000). Aging of the brain and its impact on cognitive performance: Integration of structural and functional findings. In F.I.M. Craik \& T.A. Salthouse (Eds.), The handbook of aging and cognition (2nd ed., pp. 1-90). Mahwah, NJ: Lawrence Erlbaum Associates Inc.

Salthouse, T.A. (1978a). Adult age and the speed-accuracy trade-off. Ergonomics, 22, 811812.

Salthouse, T.A. (1978b). Age and speed: The nature of the relationship. Unpublished manuscript, Department of Psychology, University of Missouri, Columbia, MO.

Salthouse, T.A. (1985). Speed of behavior and its implications for cognition. In J.E. Birren \& K.W. Schaie (Eds.), Handbook of the psychology of aging (2nd ed., pp. 400-426). New York: Van Nostrand Reinhold.

Salthouse, T.A. (1988). Initiating the formalization of theories of cognitive aging. Psychology and Aging, 3, 3-16.

Salthouse, T.A. (1996). The processing-speed theory of adult age differences in cognition. Psychological Review, 103, 403-428.

Salthouse, T.A., Babcock, R.J., \& Shaw, R.J. (1991). Effects of adult age on structural and operational capacities in working memory. Psychology and Aging, 6, 118-127.

Salthouse, T.A., \& Meinz, E.J. (1995). Aging, inhibition, working memory, and speed. Journal of Gerontology: Psychological Sciences, 50, P297-P306.

Salthouse, T.A., \& Somberg, B.L. (1982). Time-accuracy relationships in young and old adults. Journal of Gerontology, 37, 349-353.

Schumacher, E.H., Lauber, E.J., Glass, J.M., Zurbriggen, E.L., Gmeindl, L., Kieras, D.E., \& Meyer, D.E. (1999). Concurrent response selection processes in dual-task performance: Evidence for adaptive executive control over task-scheduling strategies. Journal of Experimental Psychology: Human Perception and Performance, 25, 791-814.

Schweickert, R., \& Boruff, B. (1986). Short-term capacity: Magic number or magic spell? Journal of Experimental Psychology: Learning, Memory, and Cognition, 12, 419-425.

Scialfa, C.T. (2000, April). Relations between sensceptual and cognitive aging. Paper presented at the Cognitive Aging Conference, Atlanta, GA.

Scialfa, C.T., Hamaluk, W., Skaloud, P., \& Pratt, J. (1999). Age differences in saccadic averaging. Psychology and Aging, 14, 695-799.

Sliwinski, M.J. (1997). Aging and counting speed: Evidence for process-specific slowing. Psychology and Aging, 12, 38-49.

Smith, E.E., \& Jonides, J. (1999). Storage and executive processes in the frontal lobes. Science, 283, 1657-1661.

Somberg, B.L., \& Salthouse, T.A. (1982). Divided attention abilities in young and old adults. Journal of Experimental Psychology: Human Perception and Performance, 8, 651663.

Standing, L., Bond, B., Smith, P., \& Isely, C. (1980). Is the immediate memory span determined by subvocalization rate? British Journal of Psychology, 71, 525-539. 
Stolzfus, E., Hasher, L., Zacks, R., Ulivi, M., \& Goldstein, D. (1993). Investigation of inhibition and interference in younger and older adults. Journal of Gerontology: Psychological Sciences, 48, 179-188.

Strayer, D.L., \& Kramer, A.F. (1994). Aging and skill acquisition: Learning-performance distinctions. Psychology and Aging, 9, 589-605.

Strayer, D.L., Wickens, C.D., \& Braune, R. (1987). Adult age differences in the speed and capacity of information processing: II. An electrophysiological approach. Psychology and Aging, 2, 99-110.

Sullivan, M.P., \& Faust, M.E. (1993). Evidence for identity inhibition during selective attention in old adults. Psychology and Aging, 8, 589-598.

Surwillo, W.W. (1963). The relation of simple response times to brain wave frequency and the effects of age. Electroencephalography and Clinical Neurophysiology, 15, 105-114.

Talland, G.A. (1967). Age and the immediate memory span. The Gerontologist, 7, 4-9.

Tipper, S.P. (1991). Less attentional selectivity as a result of declining inhibition in older adults. Bulletin of the Psychonomic Society, 29, 45-47.

Van Boxtel, M.P.J., van Beijsterveldt, C.E.M., Houx, P.J., Anteunis, L.J.C., Metsemakers, J.F.M., \& Jolles, J. (2000). Mild hearing impairment can reduce verbal memory performance in a healthy adult population. Journal of Clinical and Experimental Neuropsychology, 22, 147-154.

Verhaeghen, P., \& De Meersman, L. (1998). Aging and the Stroop effect: A meta-analysis. Psychology and Aging, 13, 120-126.

Wechsler, D. (1981). Manual for the Wechsler Adult Intelligence Scale-revised. New York: The Psychological Corporation.

Welford, A.T. (1977). Motor performance. In J.E. Birren, \& K.W. Schaie (Eds.), Handbook of the psychology of ageing (pp. 450-496). New York: Van Nostrand Reinhold.

West, R.L. (1996). An application of prefrontal cortex function theory to cognitive aging. Psychological Bulletin, 120, 272-292.

West, R., \& Baylis, G.C. (1998). Effects of increased response dominance and contextual disintegration on the Stroop interference effect in older adults. Psychology and Aging, 13, 206-217.

Wingfield, A., Stine, E.L., Lahar, C.J., \& Aberdeen, J.S. (1988). Does the capacity of working memory change with age? Experimental Aging Research, 14, 103-107.

Woodruff, D.S. (1975). Relationships among EEG alpha frequency, reaction time, and age: A biofeedback study. Psychophysiology, 12, 673-681. 


\section{APPENDIX}

\section{AN ILLUSTRATIVE EPIC PRODUCTION RULE}

This production rule illustrates possible $\mathrm{WM}$ items, rule conditions, and actions in EPIC:

\section{IF}

\section{( (GOAL DESIGNATE TARGET)}

(STRATEGY MAKE POKE IMMEDIATELY)

(STEP MAKE POKE-RESPONSE )

(TAG ?OBJECT IS STIMULUS)

(VISUAL ?OBJECT COLOR RED)

(NOT (VISUAL ??? SIZE LARGE))

(STATUS PERF - TACTICAL RESPONSE-PROCES S HAS EYE)

(MOTOR MANUAL PROCESSOR FREE))

\section{THEN}

( (SEND - TO - MOTO R MANUAL PERFORM POKE (LEFT INDEX) ?OBJECT)

(ADDDB (GOAL WATCH - FOR DESIGNATION - EFFECT )

(DELDB (STEP MAKE POKE-RESPONSE))

(ADDDB (STEP WAIT-FOR WATCHING-DONE) ))

The function of this rule is to touch a small red object on a display screen, designating it as a target by poking it with the left index finger. Embedded in the rule's conditions are multiple expressions that must be true conjunctively with respect to the contents of WM: Here, the goal (control-store item) is to designate a target; the strategy (control-store item) is to make the poke movement immediately; the current procedural step (control-store item) calls for making a poke movement; a certain visual object has been tagged as "the stimulus" (tag-store item); the tagged stimulus object (visual WM item) is red; no large object is in view (i.e., visual WM lacks any items about "large" objects); the process responsible for making the poke has a status (control-store item) that enables it to move EPIC's eye; and the state of the manual motor processor (control-store item) indicates that it is free to accept movement commands. If and when EPIC's various WM stores contain all requisite items for matching this rule's conditions, then one of the rule's actions will command the manual motor processor to make a poke movement with the left index finger at the stimulus object. Also, the rule's other actions will establish a new subgoal (control-store item) to be accomplished next, delete the current step item, and add an item for the next step. 